\title{
EL LEGADO CIENTÍFICO DEL LICENCIADO GEÓMETRA PEDRO NOLASCO GUTIÉRREZ GUTIÉRREZ (1855-1918)
}

\author{
Ronald E. Díaz Bolaños ${ }^{1 *}$, Flora J. Solano Chaves $^{2} \&$ Giovanni Peraldo Huertas ${ }^{3}$
}

\author{
${ }^{1}$ Escuela de Historia y Centro de Investigaciones Geofísicas de la \\ Universidad de Costa Rica. \\ ${ }^{2}$ Centro de Investigaciones Geofísicas de la Universidad de Costa Rica. \\ ${ }^{3}$ Escuela Centroamericana de Geología, Universidad de Costa Rica. \\ *Autor para contacto:roeddibo@yahoo.com
}

(Recibido: 20/03/07; aceptado: 20/11/07)

\begin{abstract}
Pedro Nolasco Gutiérrez Gutiérrez (1855-1918), Licentiate, Geometer, prominent scientific figure of Costa Rica between late 19th century and early 20th century. This article pretends to analyze his biography, his scientific work and the impact of his intellectual activities in the Costa Rican society in that time. Don Pedro knew about the astrometeorology, the geology and the seismology and used the first field for forecasting earthquakes and the climate conditions. Dr. Henri Pittier, Chairman of the National Physical Geographic Institute of Costa Rica, critized this methodology. The diffusion of Gutiérrez calendars converted him in the most popular scientific person during this period. Although, today the earthquakes prediction is very difficult to analyze, but is very important to study the methodology used by Pedro Gutiérrez because he predicted some quakes. For this knowledge, was named, "Brujo del Observatorio".

Key words:Astrometeorology, sismology, biography, politic.

RESUMEN: El presente artículo versa sobre la vida del Lic. don Pedro Nolasco Gutiérrez Gutiérrez prominente figura científica de la Costa Rica de finales del siglo XIX y de principios del siglo XX. Don Pedro accedió al conocimiento de la astrometeorología, a la geología y la sismología. La astrometeorología la usó como una herramienta para la predicción de sismos. Esta idea no obstante, fue debatida por el Dr. Henri Pittier, en ese entonces, director del Instituto Físico Geográfico. Nació don Pedro en Puntarenas en 1855 y murió en la ciudad de San José en 1918. Laboró en el Instituto Físico Geográfico (IFG). Es importante indicar que de todos los científicos costarricenses de esa época, fue don Pedro Nolasco, que sin querer, se acercó al pueblo mediante su almanaque y fue sin duda la figura científica más popular de la época. Aunque actualmente se indica que las predicciones sísmicas están aún lejanas, es importante, no obstante, seguir indagando la visión de don Pedro, pues acertó en varias de sus predicciones, de ahí que la población lo empezara a llamar "El Brujo del Observatorio".

Palabras clave: Astrometeorología, sismología, biografía, política.
\end{abstract}


“[...] la astronomía y la meteorología ...proféticas, en $<<$ don Pedrito >> Nolasco Gutiérrez $[\ldots] ”$

Segarra y Juliá (1907:220).

[...] sin querer alarmar, don Pedro Nolasco [Gutiérrez] dice que siempre es bueno temer algo del 10 al 12 y luego del 14 al 24 [de mayo de 1910]. Esto por cálculos que tiene de series de temblores y épocas que coinciden con el estado planetario actual é influencia que pueda establecer en él la presencia del cometa [Halley].

La Prensa Libre, 9-V-1910:3 (Cit. pos Molina Jiménez, 2005:253).

\section{INTRODUCCIÓN}

Gran notoriedad y espectacularidad por su brillantez causó el avistamiento del cometa Halley al aproximarse al planeta Tierra en 1910. Este fenómeno y en general, los cometas han suscitado una serie de supersticiones en la población, al punto que en muchas culturas se les relaciona como mensajeros de grandes males. Entre los cometas inspiradores de presagios ha sido el Halley por su periodicidad de tres cuartos de siglo con los que se aproxima a la Tierra (Ocampo, 1989). Su presencia generó temor, angustia y admiración entre los observadores a nivel mundial, particularmente cuando la prensa difundió la tesis de científicos como la del astrónomo francés Camil Flammarion (1842-1925), que al calcular la trayectoria del cometa determinó que el extremo de su cola alcanzaría la Tierra, temiéndose el posible influjo de gases venenosos en la atmósfera terrestre (Paluzíe Borrell, 1984:164-165 y Molina Jiménez, 2005:235-236).

La anterior tesis fue compartida y difundida en Costa Rica por el Lic. Geóm. Pedro Nolasco Gutiérrez Gutiérrez (1855-1918) (Fig. 1), uno de los principales estudiosos de los fenómenos astronómicos, meteorológicos y sismológicos en el país. Gutiérrez era conocido por los motes de "Sabio brujo" o "Brujo del Observatorio", según atestigua el Prof. José Fidel Tristán $(145,1916: 13)$.

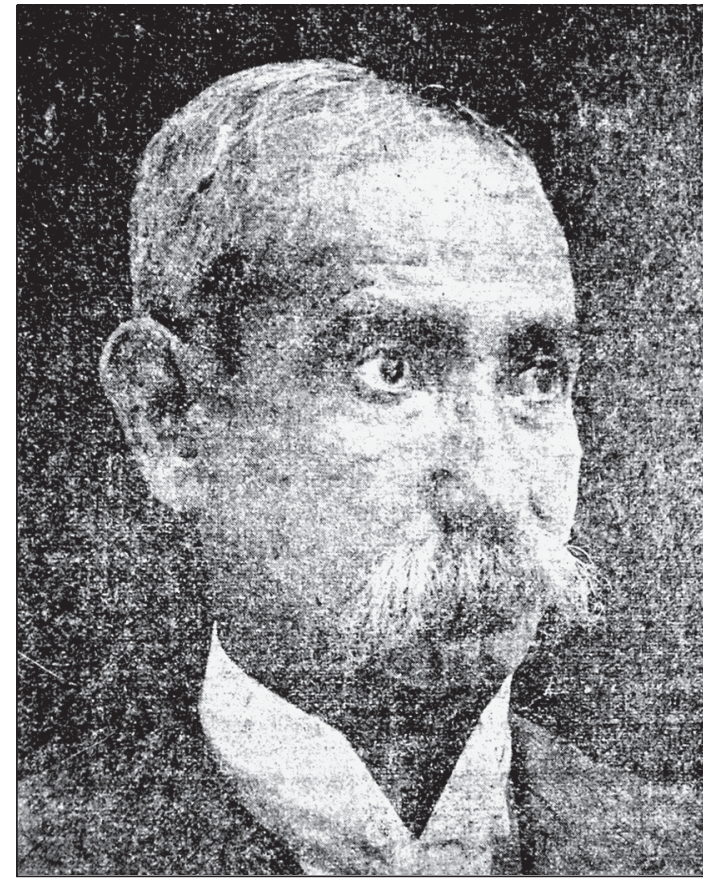

Fig. 1: Lic. Geómetra Pedro Nolasco Gutiérrez, tomado del periódico La Información del 2 de febrero de 1916, página 5.

Otros investigadores que compartían las tesis difundidas por Gutiérrez sobre el estudio y análisis de los posibles impactos del cometa Halley en 1910 fueron el Ing. Luis Matamoros Sandoval (1859-1934), investigador que aplicó el conocimiento científico para el desarrollo de las obras públicas y el Ing. Manuel Víctor Dengo Bertora (1840-1925), uno de los artífices del desarrollo eléctrico en Costa Rica (Díaz, 2003:91; Molina Jiménez, 2005:246-247; Obregón, 2005:69 y 273-274 y Goebel, 2006). Con relación a la comunión de ideas entre Nolasco y Matamoros está como prueba el siguiente extracto periodístico "... don Pedro se propone de hoy en adelante [20 de abril, 1910] medir y calcular, antes que observar, la posición del Halley con el ingeniero don Luis Matamoros..."(El Independiente, 20 de abril de 1910).

Una perspectiva teórico-metodológica divergente fue la del Dr. Juan Rudín (1849-1932), científico y profesor suizo radicado en el país, quien combatió duramente las supuestas consecuencias que traería el cometa para la Tierra (Molina Jiménez, 2005:233-234). 
En este mismo año de 1910 en que se avistó el cometa Halley, específicamente durante el primer semestre y acorde con la evidencia histórico-científica, el país vivió una relevante actividad sísmica que tuvo como evento más significativo el terremoto de Cartago del 4 de mayo de ese año, fenómeno que provocó la destrucción de la ciudad y la muerte de 272 personas (Cf. González Víquez, 1910:139-158; Calvert \& Calvert, 1917:475-491, Montero, 1984 y Miyamura, 1980:124-125). La creencia inmemorial de atribuir a los cometas y supernovas la generación de eventos extremos resurgió entre las clases populares del país quienes vieron en el Halley la causa del violento sismo. Además, desde la época colonial, era común en la mentalidad de los moradores del Valle Central costarricense, asignar un origen sobrenatural a los eventos sísmicos y meteorológicos, asociándolos con malas cosechas, epidemias y muertes (Molina Jiménez, 2005:259-262 y cf. Rodríguez, 2005).

En este mismo período, el debate de ideas científicas en torno a las posibles consecuencias de la aproximación del Halley trascendió a la opinión pública, precisamente, la figura del Lic. Gutiérrez alcanzó notoriedad en esta coyuntura. A pesar de su legado en el desarrollo científico costarricense, este ha sido poco investigado o enfocado desde la perspectiva de la historia cultural obviando el aspecto científico (Molina Jiménez, 1994 y 2005). Por ello, el presente artículo pretende dilucidar este aporte desde el punto de vista de la historia social de la ciencia, cuyo enfoque, de acuerdo con Saldaña (1996:7-8):

[...] pretende llegar a entender la naturaleza y el comportamiento que han seguido los grupos sociales (los científicos) que crean, desarrollan o incorporan conceptos y teorías en un contexto social particular y como consecuencia del mismo. Se presta atención igualmente a aquellos aspectos generales de la sociedad y de la geografía regionales (orden social, cultura, recursos naturales, posiciones geográficas, etcétera) que son responsables de las actitudes grupales hacia la ciencia y que le han impuesto un estilo particular [...]

En esta perspectiva teórico-metodológica también se debe acotar el papel de la comunidad científica que envolvía las actividades ejercidas por Gutiérrez. Rodríguez-Sala (2004:15, cf. Viales y Clare, 2006-2007:149) la define bajo las siguientes condiciones:

1) un principio de autoridad que se ubica, precisamente, en esa comunidad. Es dentro de ella en donde se realiza, se juzga y se valora toda actividad científica, sin permitir ningún tipo de intromisión externa.

2) la existencia de y el compartir, un sistema de creencias acerca de la ciencia.

3) la importancia que reviste el papel social de la actividad científica y que se manifiesta por la existencia de un patrón de conductas, sentimientos y motivaciones concebidos como unidades de interacción social, que entraña el reconocimiento o legitimación de esa actividad por parte del resto o cuando menos de una parte de la sociedad en que se realiza.

Es preciso indicar que de acuerdo a investigaciones recientes (Solano, 1999; Peraldo, 2003; Díaz, 2003; Solano y Díaz, 2005) los factores externos dinamizan, cohesionan y consolidan la configuración de una comunidad científica. En esta perspectiva, debe entenderse la comunidad científica como aquella entidad conformada por investigadores y estudiosos con formación científica capaces de producir conocimiento científico y difundirlo a través de publicaciones que circulan dentro y fuera del país al que pertenecen. Los miembros de una comunidad científica debaten aquellos puntos en desacuerdo sobre un nuevo conocimiento, laboran parcial o exclusivamente para instituciones científicas y pertenecen a sociedades científicas nacionales o extranjeras. Mediante la publicación de los resultados de sus investigaciones pueden mantener contactos con sus pares a nivel internacional.

Lógicamente, las luchas de poder están presentes al interior de una comunidad científica donde sus miembros interactúan en condiciones de desigualdad frente a la apropiación del producto del trabajo científico (Bourdieu, 2000:32, cit. pos Viales y Clare, 2006-2007:150). En el caso latinoamericano, como lo señalan Vessuri y Capel (cit. pos Viales y Clare, 2006-2007:150), el Estado brindó un apoyo explícito o implícito a las comunidades científicas en la medida en que estas participaban en la organización de los 
nuevos territorios mediante la exploración de sus recursos potenciales.

Bajo esta perspectiva, el presente trabajo se subdivide en cinco secciones en las que se circunscribe la trayectoria científica del Lic. Gutiérrez: I) El contexto histórico-científico de mediados del siglo XIX. II) Su formación científica. III) Su relación con las instituciones científicas establecidas al finalizar el siglo XIX. IV) Sus aportes durante el ocaso de su carrera. V) Su concepción de la sismología. VI) Aspectos de la vida cotidiana de su tiempo relacionados con sus estudios.

Esta investigación se efectuó gracias al apoyo institucional del Centro de Investigaciones Geofísicas (CIGEFI) de la Universidad de Costa Rica a través del Proyecto Meteorología e Impacto Social Ambiental en Centro América y México (MISCAM, VI-805-97-519) y del Programa Estudios Sociales de la Ciencia, la Técnica y el Medio Ambiente (PESCTMA, VI805-A4-906), en el que también colaboran el Centro de Investigaciones Históricas de América Central (CIHAC) y la Escuela de Historia de la Universidad de Costa Rica. Además, las investigaciones en el ámbito sismológico fueron canalizadas mediante el apoyo de la Escuela Centroamericana de Geología.

\section{La ciencia en Costa Rica al promediar el siglo XIX}

En el siglo XIX, el concepto de ciencia se definía como: "El conjunto de todos los conocimientos del hombre" (AMNCR, 7999:10). Posteriormente, en la primera mitad del siglo $\mathrm{XX}$, la ciencia se redefine como un corpus "de doctrina metódicamente formado y ordenado, que constituye un ramo particular del humano saber" (Espasa-Calpe, XIII:135). Estas concepciones de la ciencia se traslapan de Europa y América del Norte a los países de América Latina, región fuertemente influenciada por enfoques teóricos foráneos que originan investigaciones tradicionales como las de Eakin (1999:123-124), centradas en aspectos cronológicos que conciben el desarrollo científico latinoamericano como un producto expansivo europeizante en el Nuevo Mundo. Esta fase coincide con el influjo de la industrialización generando una connotación "mesiánica" en el pensamiento científico a merced del incremento de científicos exploradores a la región quienes conciben la ciencia como un instrumento capaz de redimir los pueblos "atrasados" (Cf. Pyenson, 1985).

En contraposición a las investigaciones anteriores, los estudios de la historia social de la ciencia en torno al desarrollo histórico-científico en América Latina, ubican sus raíces en las culturas antiguas de la región y perciben una simbiosis con el pensamiento occidental a partir del siglo XVI durante el proceso de conquista y colonización del Nuevo Mundo. Estas condiciones generan las bases de un marco científico regional autóctono capaz de nutrir el marco científico universal (Saldaña, 1989 y 1996; Azuela, 1995 y 1996; Vessuri, 1996; Weinberg, 1996; Azuela y Guevara, 1998; Azuela et al., 1999; Solano, 1999; Peraldo, 2003 y Rodríguez-Sala, 2002a y b, 2004a y b, 2005a, b y c y Díaz, 2003).

La Costa Rica de mediados del siglo XIX preparaba su participación en la campaña bélica contra las fuerzas filibusteras de William Walker (1824-1860) entre 1856 y 1857. Mientras la sociedad costarricense enfrentaba su principal coyuntura militar en el siglo XIX, la presencia de un grupo de científicos, profesionales y estudiosos constituyó el núcleo inicial de una comunidad científica que contaba en ese momento con la participación de dos destacados investigadores alemanes: el Dr. Alexander von Frantzius (1821-1879) y el Dr. Karl Hoffmann (18231859), quienes ingresaron a Costa Rica en 1854 , llevando consigo dos cartas de recomendación para el presidente Juan Rafael Mora Porras (1814-1860). Una de ellas, escrita por el insigne científico barón Alexander von Humboldt (17691859) y la otra, por el Dr. Nees von Eesenbeck (1776-1858), Director de la Academia Imperial de Ciencias de Prusia (Solano, 1999:129-130 y Hilje, 2006:27-28).

Los aportes de Frantzius y Hoffmann se centraron en la recopilación de datos para el conocimiento de la meteorología, la geología, la botánica y la zoología de Costa Rica, además de prestar sus servicios para el ejército costarricense durante la Campaña Nacional (1856-1857) y en la fundación de instituciones como la Botica 
Francesa en cuyo gabinete se forjaron vocaciones científicas como las del Dr. José Cástulo Zeledón Porras (1846-1923), su esposa Amparo LópezCalleja de Zeledón (1863-1957) y los profesores Anastasio Alfaro González (1865-1951) y José Fidel Tristán Fernández (1873-1932) (Frantzius, 1967; Hoffmann, 1976; Mata, 1992:77-78; Coronado, 1997:259; Palmer, 2003:61-64 y Hilje, 2006:38,41-42,80-82 y 117-172).

La llegada de Frantzius y Hoffmann se vincula con el arribo de varios inmigrantes alemanes a Costa Rica, principalmente empresarios, políticos y colonizadores, quienes al abandonar el Viejo Continente por aspectos políticos buscan en el territorio costarricense un lugar donde rehacer sus vidas y empresas. La expansión cafetalera y la ampliación de las actividades agrícolas en extensas áreas del suelo patrio ampliaron su panorama. Entre dichos inmigrantes varios destacan por su formación científica, algunos residieron en el país en forma temporal o permanente y sus trabajos e investigaciones fueron un aporte para estructurar la comunidad científica costarricense. Sobresalen, por ejemplo, el barón Alexander von Büllow (¿1799?-1856), el Ing. Ludwig Daser (m. 1862), el Ing. Franz Kurtze (m. 1868), el Dr. Friedrich Streber (1809- ¿?), el Cap. Franz Rohrmoser von Chamier (1836-1919) y el escritor Wilhelm Marr (1819-1904) (Herrera, 1988:97-115; Solano y Díaz, 2005:29-30 y Hilje, 2006:29-39).

Además, la presencia de un contingente de médicos nacionales y extranjeros, residentes en el país, encabezados por el guatemalteco Dr. Nazario Toledo Murga (1807-1887), impulsa el surgimiento de instituciones como el Protomedicato de Costa Rica, fundado en 1857, con la finalidad de normar la práctica de las ciencias médicas en el país (Blanco, 1997:165-171; Palmer, 2003:52-56 y Viales, 2003:45-49).

El Protomedicato de Costa Rica vino a sumarse al creciente número de entidades que promovían el desarrollo de políticas estatales fundamentadas en ideas científicas entre las que descollaban: 1) la Sociedad Económica Itineraria, creada con la meta de dotar al país de una red vial. 2) la Universidad de Santo Tomás, centro generador de los cuadros políticos y administrativos del naciente Estado. 3) la Sociedad Berlinesa de Colonización, para establecer colonias alemanas en el suelo costarricense. Todas estas instituciones fueron establecidas en 1843 , poco después del fracaso de la experiencia unionista del presidente Gral. Francisco Morazán (1792-1842), permitiendo a las autoridades encabezadas por el Jefe de Estado, José María Alfaro Zamora (1799-1856) proseguir el proyecto político y económico iniciado en la década anterior por Braulio Carrillo Colina (1800-1845) de cimentar las bases del Estado nacional costarricense (Calderón, 2002:242-253).

En esa misma época, la prensa inicia la publicación de información científica como las "Afecciones astronómicas", un recuento de las efemérides diarias y también, la aparición de un cuadro sobre diferencias climáticas de acuerdo con la latitud del observador (EMC, 17-VIII1844:224 y 19-VII-1845:372).

La astronomía sería en esta fase una de las ciencias a las que mayores aportes brindaría el Lic. Pedro Nolasco Gutiérrez. Siendo tan solo un niño de aproximadamente dos años (1857), descendió del firmamento un meteorito hallado en las proximidades de Heredia y Alajuela. Sus fragmentos fueron enviados fuera del país para ser analizados. El científico polaco Ignacio Domeyko Ankuba (1802-1889) publicó un trabajo en Chile donde comparaba la muestra del meteorito caído en Costa Rica con una similar importada de Francia y al compararlas confirmó la idea de la universalidad de los elementos de la naturaleza (Soto, 2004; Vargas, 2006 y Solano, Díaz y Fernández: en este trabajo). Domeyko recibió los fragmentos del meteorito de Costa Rica por parte del diplomático y estudioso chileno Francisco Solano Astaburuaga (1817-1892), quien fue comisionado por el gobierno de Chile, para promover la adhesión del gobierno costarricense al Tratado de Unión Americana suscrito por varios Estados suramericanos (1856) ante una eventual expansión norteamericana en la zona a raíz de la presencia filibustera en Centroamérica.

Un análisis de los procesos anteriores evidencia la existencia de una comunidad científica y la realización de actividades relacionadas con la ciencia en el país, las que fueron aprovechadas por el Lic. Pedro Nolasco Gutiérrez en su juventud para desarrollar su talento científico. 


\section{Formación científica del Lic. Pedro Nolasco Gutiérrez}

Escasa información se tiene sobre los primeros años de vida del Lic. Pedro Nolasco Gutiérrez. Los microfilmes de los libros sacramentales pertenecientes al Archivo Histórico Arquidiocesano, correspondientes a la ciudad de Puntarenas, registran su nacimiento el 18 de mayo de 1855 (AHAMBATH. T-001:2:26,43). En ese entonces Puntarenas era un floreciente puerto del Pacífico dedicado a la exportación del café y a la introducción de artículos manufacturados procedentes de Estados Unidos, Europa y los países de la costa pacífica de América Latina. El Supremo Gobierno lo declaró puerto franco en 1847 para incrementar el tráfico de buques, pasajeros y mercancías, por lo que esta naciente ciudad fue dotada de una gobernación y se transformó en la sede de numerosas casas comerciales nacionales y extranjeras que operaron en el principal puerto del país (Valverde, 1997:39-48).

El científico alemán Moritz Wagner (18131887) resume su visita a Puntarenas en 1853 como una ciudad donde:

[...] las calles laterales quedan pobres chozas de caña, techadas con hojas secas de palmeras; en ellas viven los pescadores y jornaleros, en su mayor parte indios o medio indios. La iglesia está situada en una plaza abierta, cubierta de plantas salmueras. Es una barraca de madera que se parece a pósitos alemanes, con un campanarito que descansa en cuatro estacas y que me hizo la impresión de unos centinelas cosacos en el Kubán, o bien de un palomar alemán [...] El correo es un edificio de buena presencia, rodeado de un grupo hermoso de palmeras de coco con fuertes copas [...] La casa particular más bonita es la del Sr. [Crisanto] Medina; es éste un rico comerciante y finquero de Miravalles, conocido también en Alemania por sus ensayos de atraer colonos alemanes a la Meseta de Miravalles [...] Punta Arenas [sic] es un lugar favorable para el comercio al menudeo, especialmente las bebidas alcohólicas encuentran aquí, en proporción al número de habitantes, una salida increíble. (Scherzer y Wagner, 1944:260)

El sitio descrito por Wagner dio abrigo al padre de Pedro Nolasco, el marino Pedro Gutiérrez (m. 1897), capitán del puerto de Puntarenas. Propietario de un buque, bautizado con el nombre de General Guardia, por el parentesco existente entre su familia y la del político y militar Gral. Tomás Guardia Gutiérrez (1831-1882). Guardia había asumido el poder el 27 de abril de 1870, coyuntura que favorecería la inserción del joven Gutiérrez en la vida pública (Oconitrillo, 1985:156). El buque General Guardia fue adquirido en 1875 para dedicarlo al transporte del correo entre las distintas poblaciones del Golfo de Nicoya, que tenían a Puntarenas como principal nodo de una importante red comercial que enlazaba las poblaciones costeras de la zona (Sáenz Maroto, 1970:477). Además, esta embarcación transportó la correspondencia de Liberia y otros pueblos de la provincia de Guanacaste, cuyas actividades económicas se vieron favorecidas por el uso de la ruta del río Tempisque y sus afluentes como vía de comunicación.

Es factible que el niño Nolasco viajara con su padre en esta embarcación y en otras que surcaban el Golfo de Nicoya, en una época en que éste experimentaba un activo comercio. La belleza de sus costas pudo haber despertado su vocación por los conocimientos científicos. Wagner (1944:263) describe el Golfo de Nicoya como:

La vista desde la Punta, hacia el Golfo de Nicoya es, especialmente en dirección norteña y occidental, sumamente hermosa.

Allende de la punta de tierra queda la isla de San Lucas, que posee lindos contornos, guarnecidos de bahías, y que se levanta encima del flujo azul del golfo [...] Más hacia el Noroeste se ven los contornos de las Islas Caballo y Bejuco [...] Casi todas estas islas están cubiertas de altos árboles y densa vegetación; ya desde lejos se divisa el blanco anillo de la rompiente espumosa que brota en sus escollos, que desaparece y vuelve, dándoles así a estas islas una apariencia de movilidad.

En esta misma zona, el Dr. Karl Hoffmann establece su hogar en febrero de 1859. Su traslado a Puntarenas se justifica por los beneficios que traería para su salud las condiciones climáticas. No obstante, su enfermedad se agrava, su esposa Emilia fallece durante una epidemia local de tifoidea y poco tiempo después, el científico muere el 11 de mayo de ese mismo año (Hilje, 2006:67). 
Cabe preguntarse: ¿Qué influencia tuvo Hoffmann en el despertar de la vocación científica del Lic. Gutiérrez? ¿El Cap. Pedro Gutiérrez habrá tenido algún tipo de contacto con el Dr. Hoffmann? ¿El niño Pedro Nolasco habrá conocido al científico? La evidencia histórica no lo comprueba pero la presencia de Hoffmann y los Gutiérrez en este puerto durante la misma época podría sugerirlo.

Es factible que el niño Pedro Nolasco Gutiérrez haya recibido su educación primaria en dicho puerto. De acuerdo con Valverde (1997:122-123), sus moradores solicitaron al gobierno la asignación de un maestro y el producto de dicha gestión favoreció la apertura de una escuela para niños varones en la segunda mitad del siglo XIX.

De su temprana juventud no existe mayor información de los estudios pero sí de su primer trabajo científico: un conjunto de datos conservados en el Archivo del Museo Nacional de Costa Rica que fueron recabados cuando era un joven de diecisiete años, referentes a la observación de lluvias, rayos y temperaturas en Puntarenas entre agosto y diciembre de 1872. Estos datos fueron comparados con los registros de temperatura analizados en San José por Friedrich Maison (1821-1881), Director interino de la Oficina de Estadística, quien publicaba sus investigaciones en tablas mensuales (AMNCR, 8543:213-214). Esta oficina, fundada en 1861, recibió la misión de recabar los datos meteorológicos oficiales producidos en el país (Solano, 1999:152).

En ese mismo período, las autoridades del puerto de Puntarenas ponen en marcha un sistema de señales meteorológicas en el decenio de 1870 . Este método es una adaptación del desarrollado por el Gral. Albert J. Myer (1828-1880) para el ejército de los Estados Unidos. Su principal producto fue el Reglamento Interior para el servicio del Vapor Nacional de Guerra Irazú (1879), documento cuyo apartado titulado "Reglamento para el Guardia en Puerto", en que se indica en el inciso 16 (Solano, 1999:159-161):

Debe anotar el cambio del viento, del tiempo y movimiento de las nubes, posición del barómetro y termómetro. Esto lo hará cada cuatro horas.

Además, el "Reglamento para los Cuartelmaestres" especifica la función del Cuartelmaestre de Señales e incluye el cuidado del termómetro y el barómetro para las observaciones meteorológicas del puerto (Solano, 1999:160). Esto demuestra la sistematicidad en el cuidado y toma de datos relacionados con aspectos meteorológicos, aspecto que denota la preocupación gubernamental por aplicar, en la medida de lo posible, las exigencias mínimas para la toma de datos relacionados con el clima. Cabe preguntarse si el joven Gutiérrez tuvo conocimiento de dicho sistema y si desempeñó en algún momento la función de Cuartelmaestre. Es factible que la residencia de Gutiérrez en una ciudad portuaria durante los primeros años de su vida pudo haber incidido en la producción de uno de los primeros trabajos de meteorología marina y registros de mareas para Puntarenas publicados en Costa Rica al finalizar el siglo XIX (LPL, 30-VIII-1890:2 y LUC, 17-II-1897:142).

Debe indicarse que el vapor Irazú era utilizado por el General Tomás Guardia y su comitiva para hacer travesías y visitas exploratorias con el fin de estudiar e integrar regiones alejadas al movimiento de la vida social y mercantil del Valle Central. Obviamente debía mantenerse en buenas condiciones y apegado a las últimas normas establecidas para la navegación (Solano, 1999:160).

Más adelante, el joven Gutiérrez pudo haber complementado sus estudios en San José. Este dato se deduce a partir de la descripción hecha por el escritor Ramón Céspedes (1937:30-31), quien nombra a Gutiérrez entre los discípulos más connotados del físico italiano Rodolfo Bertoglio (1844-1887), profesor de la Cátedra de Matemáticas del Instituto Nacional y de la Escuela de Ingeniería de la Universidad de Santo Tomás. Bertoglio fue también maestro de destacados ingenieros costarricenses formados en esa época, entre ellos: Salomón Escalante (1843-1928), Luis Matamoros Sandoval (18591934), Nicolás Chavarría Mora (1865-1927) y Carlos Francisco Salazar Salazar (1851-1908), profesor de Matemáticas (Oconitrillo, 1985:162; Páez, 1994:64-65; Barrantes y Ruiz, 1995:50-53; Rodríguez y Ruiz, 1995:23 y Obregón Quesada, 2005:61-64).

En esos mismo años, Pedro Nolasco Gutiérrez debió recibir la influencia del astrónomo Guillermo Molina Molina (¿1835?-1889), una figura poco conocida de la comunidad científica costarricense. Molina, nacido en la ciudad 
de Cartago, procedente de una familia de extracción social humilde y dirigida por una madre soltera, fue también tenedor de libros e impresor. Su vocación científica fue autodidacta, según se desprende de un análisis de la oración fúnebre pronunciada por el Lic. Francisco María Iglesias (1825-1903), Rector interino (1850) y Profesor de la Universidad de Santo Tomás (ANCR, 4278:1; Obregón Loría, 1955:33 y 1991:309; LPL, 10-X-1889:2):

Hijo sencillo del Pueblo: de ese Pueblo Costarricense, fecundo semillero de virtudes y de raros talentos: Pueblo apto para las ciencias, para las artes y para todo lo noble y bueno, Molina, sin más escuela que la primaria de aquellos tiempos; sin más Colegios y Universidad que su instintiva y constante aplicación á la lectura y consulta de buenos libros, y al trato social de algunas personas instruídas; de humildísimo origen, pobre y desvalido, logró sobreponerse á tan contrarios auspicios, cultivar su espíritu, y adquirir provechosos conocimientos en algunas ciencias exactas.

Molina inició los primeros estudios de sismología histórica costarricense, importó el primer telescopio que se introdujo en Costa Rica y poseyó una biblioteca de 437 volúmenes (ANCR, 4278:1-34; LPL, 10-X-1889:2; González Villalobos, 1972:99 y 160; IGN, 1989:64 y Rodríguez y Ruiz, 1995:25). Además, fue el autor del Almanaque de Costa Rica, Indicador del Tiempo para 1873, arreglado al meridiano de San José (1873) y del libro Primeras lecciones de Aritmética para uso de las Escuelas de Párvulos (1875). Estas obras, hoy día extraviadas, son citadas por el escritor y educador Luis Dobles Segreda (1891-1956) en su Índice bibliográfico de Costa Rica (1928:221-222). La primera de ellas se editó en la imprenta del autor y su contenido muestra la influencia de la astrología, incluye cómputos de datos astronómicos, vincula dichos eventos a las celebraciones religiosas de una población confesionalmente católica y que podía adquirir por este medio, alguna noción básica de la ciencia astronómica (Díaz, 2005:287-288).

$\mathrm{Al}$ analizar este almanaque, se desprende que Molina era practicante de la astrometeorología, disciplina con una de fuerte influencia hermética que mezclaba elementos científicos con aspectos esotéricos, por lo que hoy día se le considera pseudocientífica. Esta forma de conocimiento asoció el comportamiento de la atmósfera con el movimiento aparente de los astros en la esfera celeste, idea desarrollada por los babilonios, los egipcios y los chinos en la Antigüedad. Este pensamiento fue retomado y difundido en Europa por los árabes durante el período medieval, conformando una tradición cuyo auge se situó en el Renacimiento, época en que se produjeron numerosos almanaques con pronósticos astrometeorológicos de largo plazo.

En los siglos posteriores, la astrometeorología persistió hasta que empieza a ser desplazada por la meteorología moderna en el siglo XIX, al introducir métodos más modernos y sistemáticos para pronosticar el tiempo en plazos menores a los propuestos por los almanaques astrometeorológicos (Hardy et alt., 1983:184-191 y Pascual Blázquez, 2006). No obstante, la publicación de almanaques astrometeorológicos persistió, incluso en Costa Rica, donde su cultivo persistió en las primeras décadas del siglo XX ya que, como se analiza más adelante, no se introdujeron métodos más eficaces para el pronóstico meteorológico, por ello, la astrometeorología fomentó la recopilación de datos astronómicos y meteorológicos, práctica desarrollada por Molina en sus estudios.

De acuerdo con Rodríguez-Sala (2004:123), el empleo de la astrología en el pronóstico del tiempo no constituía un objeto de censura eclesiástica ni civil en el período colonial debido a que estos pronósticos no se relacionaban con la "astrología judiciaria". Este método censurado por los tribunales de la Santa Inquisición en Nueva España durante ese período, consistió en "una adivinación determinista que entrañaba la negación del libre albedrío del ser humano". Esta diferencia sustancial entre la astrometeorología y la astrología judiciaria, facilitó el desarrollo de la primera y la posibilidad de ser empleada como un método para efectuar pronósticos del tiempo utilizando los movimientos aparentes de los astros en la esfera celeste hasta la irrupción de la meteorología moderna en la segunda mitad del siglo XIX.

Los rasgos astrológicos de los registros recopilados por Molina, no eran cuestionados por la prensa de su tiempo debido a sus aplicaciones 
prácticas y no vinculadas con los pronósticos de la astrología judiciaria. Ciertamente, la prensa describe su labor meteorológica y astronómica en términos muy positivos (LPL, 10-X-1889:2):

Espíritu concentrado y analítico, su sentido predilectofue elde Observaciones Meteorológicas, unido al de la Astronomía en la parte que se relaciona con aquellas, aplicado todo á los fenómenos y variaciones de la "Meteorología y Climatología Costarricenses”.

A fuerza de estudio y de perseverancia llegó á acumular una serie considerable de datos, que aumentaba y perfeccionaba año tras año, hasta el grado que no ha existido en Costa Rica, y pasarán algunos años para que aparezca otro observador tan asiduo y tan adelantado en estos estudios especiales.

Es factible que los datos meteorológicos y astronómicos publicados en la Gaceta Oficial a mediados de la década de 1880 , sean obra de Molina por incluir pronósticos semanales junto a fenómenos astronómicos como las fases de la Luna, la salida y el ocaso del Sol y su relación con las fiestas de los santos de la Iglesia Católica y las efemérides patrias, aspectos propios de los calendarios de la época que podrían servir de medio difusor del conocimiento científico básico entre los sectores populares. Esta información empieza a publicarse a partir del 12 de agosto de 1885 como se transcribe a continuación (cf. GO, 12-VIII-1885:673):

\section{CALENDARIO. Agosto de 1885. ESTE MES TIENE 31 DÍAS DÍA 22 [sic] SOL EN VIRGO.}

Sale á las 5 h. 54 m.- Se pone á las 6 6h. m. Tiene el día 12 h. 12 m. y la noche $11 \mathrm{~h} .48 \mathrm{~m}$.

Martes 12.- Santa Clara de Asís, virgen, santa Hilaria, san Aniceto, mártir, San Herculano, obispo.

Miércoles 13.- San Alfonso María de Ligorio, obispo confesor y mártir, san Hipólito y san Casiano mártires; santa Elena mártir.

Cuarto menguante á las 9 y 3 minutos de la noche - De hoy al 16 [de agosto] lloverá muy poco - Del 17 al 19 lloverá y tronará bastante.
De acuerdo con investigaciones recientes (Solano, 1999 y Díaz, 2003), es verosímil que Molina mantuviera intercambio de información con miembros de la comunidad científica como Streber, Kurtze, Maison y el profesor español Enrique de Mira Villavicencio (i ?) para registrar datos meteorológicos y realizar pronósticos de largo plazo que eran los únicos disponibles en la Costa Rica de la época.

Los datos que Molina recopiló, hoy día se encuentran extraviados, pérdida lamentable atribuible al desinterés del Dr. Henri Pittier Dormond (1857-1950), primer director del Instituto FísicoGeográfico, quien los debió desechar por la metodología empleada en su confección. Este científico, como se analizará más adelante, refutaría las tesis astrometeorológicas del Lic. Pedro Nolasco Gutiérrez cuando le cuestiona la asociación que hacía de los sismos con las fases lunares a inicios del siglo XX.

Cabe señalar que Pittier era parte de una pléyade de científicos y profesores suizos contratados para impartir lecciones de ciencias en los colegios de enseñanza secundaria de las ciudades del Valle Central, en el contexto de la reforma educativa auspiciada por el Lic. Mauro Fernández Acuña (1843-1905), durante la administración del Gral. Bernardo Soto Alfaro (1885-1889). Otros profesores connotados de esta generación fueron el Dr. Juan Rudin, el Dr. Gustave Michaud (18601924) y el Dr. Paul Biolley (1861-1908), quienes efectuaron valiosas contribuciones al desarrolo de la Física, la Química, la Matemática, la Astronomía y la Biología en Costa Rica (Díaz y Solano, 2005:35) y la Sismología.

Curiosamente, cuando se remataron las pertenencias de Molina en su mortual, Pittier adquirió su teodolito para trabajos topográficos y desacató la recomendación del Lic. Iglesias de preservar los datos del difunto astrónomo cartaginés (LPL, 10-X-1889:2 e IGN, 1989:64):

Sensible fuera perder tan preciosos datos, y sería de desearse que fuesen recojidos [sic] $y$ utilizados por nuestro naciente Observatorio Meteorológico.

En Costa Rica, la astrometeorología estableció una forma básica de pronóstico meteorológico generado a raíz de la comparación de series de registros astronómicos con datos meteorológicos. 
La ciencia meteorológica, que en esa época incentivó metodologías más modernas que la desarrollada por la astrometeorología, no se aplicó en Costa Rica porque el Dr. Henri Pittier consideraba que el clima costarricense era lo suficientemente constante para dedicar las tareas del Instituto Meteorológico a pronosticar posibles variaciones (Díaz, 2003:82).

Frantzius (1967:10) advirtió a sus lectores de no caer en el error de considerar a los países centroamericanos como tierras donde reinaba una "eterna primavera", opinión que prevalece en el presente, debido a la aparente regularidad con que se suceden los fenómenos meteorológicos. Por el contrario, estas condiciones son modificadas por la acción de los sistemas de vientos del Caribe y del Pacífico y por el relieve, causando variaciones regionales que Frantzius identificó en sus investigaciones y Pittier no consideró en sus trabajos meteorológicos. El siguiente texto de Frantzius (1967:10) explica dicha situación:

Si, pues, la mayoría de los viajeros, provistos solamente de un termómetro juzgan del clima de un lugar por los grados de temperatura encontrados, sin acordarse del tiempo seco, pesado por el polvo y el viento, y de la estación lluviosa de ningún modo agradable por su excesiva humedad, sin tomar en consideración los restantes fenómenos meteorológicos, no es de admirar que esta errónea opinión haya silo [sic] difundida de que en Centro América efectivamente una primavera siga a la otra.

El mito de la "eterna primavera" limitó la emisión de pronósticos del tiempo por parte del personal del Instituto Meteorológico, no obstante, La Gaceta y los principales diarios nacionales, publicaron pronósticos independientes basados en los trabajos astrometeorológicos del astrónomo Guillermo Molina y continuados posteriormente por el Lic. Pedro Nolasco Gutiérrez.

Hacia finales de la década de 1870 e inicios de la de 1880, Gutiérrez desempeñó un puesto en la Aduana de Puerto Limón, gracias a la influencia de su pariente el Gral. Guardia quien ejercería la presidencia de la República hasta su muerte (1882). En esta misma época, el distante puerto del Caribe estaba siendo conectado con el Valle Central por medio del proyecto de construcción del Ferrocarril al Atlántico (Oconitrillo, 1985:156;
Murillo Chaverri, 1995; Pérez Brignoli, 1997:6163; Eakin, 1999:138 y 143; Viales, 2000:187-209 y Obregón Quesada, 2005:303-319). Esta empresa fue financiada por el estadounidense Minor Cooper Keith (1848-1929), quien emprendió la expansión del cultivo del banano en la zona y que más adelante se convertiría en la base del emporio bananero de la United Fruit Company y llegaría a ser uno de los principales gestores de la infraestructura científica del Instituto FísicoGeográfico Nacional, entidad en la que laboraría el Lic. Gutiérrez.

Tras finalizar sus funciones en la Aduana de Puerto Limón, Pedro Nolasco Gutiérrez se traslada a la capital, donde empieza a realizar modestas publicaciones en la prensa. Una de sus primeras intervenciones periodísticas es un sencillo artículo en que cuestionaba las opiniones del científico suizo Dr. Henri Pittier, poco tiempo después de su arribo al país (1887). Esta declaración se relacionaba con la crítica hecha por el suizo a las observaciones meteorológicas efectuadas en Costa Rica a lo largo de las décadas anteriores. Las críticas de Pittier provocaron un intenso debate en la comunidad científica costarricense que a su vez cuestionó la validez de sus observaciones hechas en la capital (Díaz, 2003:72-86).

La intervención de Gutiérrez publicada en el Diario costarricense el 4 de setiembre de 1888, se refería a unos datos meteorológicos que obtuvo para refutar los errores cometidos por el científico al demostrar (AMNCR, 7961: 5): "que Míster [sic] Puttier [sic] se ha equivocado de la mismísima manera que otros observadores aficionados."

Al mismo tiempo, las tensiones entre la Iglesia Católica y el Estado liberal que llegaron a su punto máximo con la promulgación de la legislación anticlerical de 1884 y el intento de la institución eclesiástica por derogarla y recuperar el espacio perdido en la esfera pública, favoreció el surgimiento del Partido Unión Católica (1890) (De La Cruz, 1984:35-36 y Salazar Mora, 1990:148-152). Esta agrupación política atrajo el interés de Gutiérrez, quien llegó a publicar numerosos trabajos de divulgación científica en las páginas de La Unión Católica, órgano informativo del movimiento antiliberal (AHAMBATH, VP, 5:187; LUC, 22X-1892:333-335 y 18-XI-1893:850). 
Entre sus publicaciones para La Unión Católica figuran el artículo "Armonía entre la ciencia y la fe" (LUC, 14-XII-1890:3) cuyo argumento combatía las tesis científicas respaldadas por los liberales que afirmaban la contradicción irreconciliable entre razón y fe, posición que se refuerza en un texto de carácter apologético, "Mentiras históricas" (LUC, 18-XII-1890:2-3):

Este mismo Kepler al adquirir tantos conocimientos se apresuró á reconocer la perfecta armonía que existe entre la ciencia y la fe, y no se avergonzaba de dirigir una pública plegaria al Creador.

En esos años, el Ing. Pedro Nolasco Gutiérrez había transmitido a su hermana, Micaela Gutiérrez Gutiérrez (¿1860-?), el conocimiento elemental para realizar observaciones meteorológicas en su natal Puntarenas. Los registros de la señorita Gutiérrez corresponden a los meses de junio a noviembre de 1892, julio a diciembre de 1894 y de enero a mayo de 1895 (AMNCR, 8543:214-215).

Aunque estos datos se encuentran incompletos, tienen la particularidad de haber sido registrados por una mujer. Estos consistían en observaciones barométricas y termométricas, pero no siempre fueron obtenidos mediante el instrumental adecuado, por lo que la señorita Gutiérrez se dedicó a recopilar datos en forma cualitativa, anotando información sobre vientos o tormentas eléctricas y utilizó un reloj para medir las horas de lluvia como lo consigna la tabla 1 (AMNCR, 8543:215):

Además, Pedro Nolasco y su hermana Micaela Gutiérrez estudiaron y analizaron el impacto de una tormenta al comienzo de la estación lluviosa de 1892 y asociaron su trayectoria a factores de índole astrológica y astronómica (AMNCR, 8543:214-215). El siguiente texto amplía los efectos de dicho evento:

La misma Señorita [Micaela] [testado: observó] anotó que el primero de Mayo [1892] hubo un fuerte aguacero no sólo en aquel puerto [Puntarenas] sino en la vecina hacienda " $\mathrm{El}$ Carrizal', y su hermano [Pedro Nolasco] observó que aquél se extendió a San Ramón, Atenas y Palmares, y que al mismo tiempo hubo una garúa en San José y que al día siguiente, teniendo la Luna 6 días y encontrándose en la constelación de Cáncer, principió la estación lluviosa en San José con un aguacero seguido de la 1 horas 10 minutos á las 5 horas 30 minutos pasado meridiano. Sin hacer mérito á la influencia lunar, nos limitamos á consignar este dato por vía de curiosidad. Los mismos observadores anotaron que el 2, 3 y 4 de [testado: Mayo] [sobrerrenglonado: dicho mes] los fuertes aguaceros no sólo se hicieron sentir en esos lugares, sino que se extendieron á Filadelfia (Guanacaste).

La publicación del Almanaque Católico Costarricense hizo célebre al Lic. Gutiérrez. Además de continuar la labor de Guillermo Molina, al incluir tópicos religiosos y científicos, información comercial y agrícola. La primera edición correspondiente al año 1893 contó con la aprobación eclesiástica de Mons. Bernardo Augusto Thiel Hoffmann (1850-1901), Obispo de San José. La difusión del calendario lo transformó en una obra muy popular entre los hogares costarricenses poniéndolos en contacto con elementos de la ciencia (LUC, 3-XI-1892:347 y 5-II-1893:2 y Fernández Mora, 1953:95).

Como era de esperar, los pronósticos meteorológicos a largo plazo eran proclives a fallar, máxime en las regiones tropicales donde los fenómenos meteorológicos evolucionan con más rapidez que en las zonas templadas del planeta. Por ello, se criticaba la inexactitud de los pronósticos meteorológicos publicados por Gutiérrez en su Almanaque, obtenidos a partir de la observación periódica del estado del tiempo y el uso de métodos de pronóstico basados en la astrometeorología (cf. Fernández Mora, 1953:95). Estos cuestionamientos eran comunes en las publicaciones astrometeorológicas de la época porque integraban elementos empíricos, científicos y astrológicos (Hardy et alt., 1983:188-190). Sin embargo, el nivel popular y periodístico le daba buen crédito, tal como lo refiere la siguiente cita: "[...] consultadas las probabilidades del tiempo en el almanaque de don Pedro Nolasco, vemos que para el día 20 anunciaba día variable ó temblores débiles, como en efecto los registró casi en su totalidad el sismógrafo" (EI, 22-IV-1910).

Además de sus contribuciones al desarrollo de la astronomía y la meteorología, los conocimientos autodidácticos de agrimensura que poseía Gutiérrez llamaron la atención del gobierno del Lic. José Joaquín Rodríguez 
Tabla 1

Precipitaciones en Puntarenas (1894)

\begin{tabular}{|c|c|c|c|}
\hline Fecha & Hora & \multicolumn{2}{|c|}{ Observaciones } \\
\hline Julio 28 & de 2 á 4 p.m. & \multicolumn{2}{|c|}{ acompañadas de truenos } \\
\hline Julio 30 & de $4 \frac{1}{2} 2$ á 5 p.m. & & \\
\hline Agosto 4 & de $4 \frac{1}{2} 2$ á 6 p.m. & id. & id. \\
\hline \multirow[t]{2}{*}{ Agosto 9} & & id. & id. \\
\hline & & & $\begin{array}{l}\text { Cayendo un rayo } \\
\text { á las } 2 \text { horas } 40 \\
\text { minutos pm }\end{array}$ \\
\hline Agosto 24 & Desde las 6 p.m. & id. & de viento fuerte. \\
\hline
\end{tabular}

Lluvias observadas en pluviómetro (m/m)

\begin{tabular}{ccccc}
\hline Día & Setiembre & Octubre & Noviembre & Diciembre \\
\hline $1^{\circ}$ & - & - & $7,2[i ?]$ & - \\
$2^{\circ}$ & - & - & 2,7 & - \\
\hline
\end{tabular}

Zeledón (1838-1917). Éste le dispensó el título de Bachiller en Ciencias y así obtener el de Licenciado Geómetra (1893) a raíz de la ausencia de una entidad de estudios superiores capaz de conferirle un título para el pleno ejercicio del oficio de agrimensor (LUC, 13-V-1893:581; Núñez, 1953:29; Sáenz Maroto, 1970:477 y Oconitrillo, 1985:155-163). Esta dispensa favoreció su posicionamiento socioeconómico y profesional porque el Congreso Constitucional otorgó al Poder Ejecutivo la potestad de conferir los títulos de Ingeniero Mecánico e Ingeniero Geómetra a los Bachilleres en Ciencias tras la clausura de la Universidad de Santo Tomás, además de cumplir las disposiciones dictaminadas por la Ley Fundamental de Instrucción Pública y la aprobación de un examen aplicado por un tribunal de ingenieros nombrados por el gobierno (Obregón Quesada, 2005:64-65).

A pesar de la fama que la astrometeorología le traería al Lic. Gutiérrez en los años siguientes por los motes populares de "Sabio brujo" o "Brujo del Observatorio", por el supuesto pronóstico del terremoto de Cartago (1910), éste fue un acérrimo enemigo del espiritismo y su propagación en círculos católicos y científicos (LUC, 3-XI-1892:345 y LI, 27-IV-1916:3, Tristán 145.13). Por su cercanía al pueblo, se le consideró una autoridad entre las capas populares (LI, 27IV-1916:3, Tristán 145.13):

el Profeta de los graades [sic] cataclismos sísmicos, seguido por las multitudes que lo sodian [¿?] a preguntas [...] Abriéndonos campo casi a la fuerza por entre el compacto grupo, llegamos hasta el centro del amplio círculo de la muchedumbre que con suma atención y religioso respeto oía las predicciones de don Pedro.

Gutiérrez, en cuanto al pensamiento científico de la época, defendía la idea del carácter unitario de la ciencia para justificar su pasión por las observaciones astronómicas, elemento que constituye una prueba más de su formación científica autodidacta, en una época donde la especialización era aun incipiente y los científicos manejaban varios campos de las ciencias físicas y naturales. Este ingeniero era abierto al debate de sus ideas, como lo muestra este extracto de su informe enviado a Pittier en 1897 (IGNCR, 1989:134):

Si se atiende al título que me da la ley de Jefe del servicio meteorológico, quizá se me critique de haberme extendido sobre observaciones que por una aberración, á mi juicio, se consideran por algunos como independientes de él. Pero aunque las haya hecho en horas extraordinarias del servicio y que puedan calificarse de mi 
propiedad particular, quiero, pues las ciencias se enlazan entre sí, contribuir aunque sea con un grano de arena al edificio científico que felizmente se levanta en mi patria á la sombra de un gobierno progresista [la primera administración del presidente Rafael Iglesias Castro], que no escatima nada para el objeto. De mi informe pueden los espiritus recalcitrantes aprovechar lo que les convenga, ó desechar ó contrastar lo que crean superfluo; del contraste me alegraría, pues puedo haber incurrido en errores que desearía conocer. Aun deseo el ensanche de las observaciones á mi cargo, siempre que se haga lo mismo con el edificio para poderlas hacer sin mayores gastos para la Nación. Tiempo para ello no me puede faltar, á mi juicio, desde el momento que estoy en la mejor voluntad para ejecutarlas sin que se me imponga como deber.

Estas ideas coincidían con los paradigmas científicos de la época, tal y como lo señala el astrónomo francés Flammarion (1883:15) en su célebre estudio meteorológico La atmósfera:

La naturaleza, estudiada racionalmente, es decir, sometida en su conjunto al trabajo del pensamiento, es la unidad en la diversidad de los fenómenos, la armonía entre todo lo criado, que difiere, por su forma, por su constitución propia, por las leyes que lo animan; es el todo empapado en un aliento vital. El resultado mas importante de un exámen racional de la naturaleza es distinguir la unidad y la armonía en esta inmensa reunión de cosas y de fuerzas, adoptar con un mismo celo lo que se debe á los descubrimientos de siglos anteriores y lo que es la obra del nuestro [XIX], analizar detalladamente los fenómenos sin dejarse abrumar por su magnitud. De esta manera puede el hombre hacerse digno de sus altos destinos; penetrando el sentido de la naturaleza, descubriendo sus secretos, dominando por medio del raciocinio, los materiales que se han recogido por medio de la observación.

El Lic. Gutiérrez fundamentaba sus análisis en las Tablas de conocimiento de los tiempos, publicadas anualmente en París, que contenían efemérides y numerosos cálculos astronómicos que él adaptaba a las coordenadas geográficas de Costa Rica (AMNCR, 8552). Muchas de las observaciones astronómicas las realizó conjuntamente con el profesor suizo Dr. Juan Rudín. Este investigador había ejercido la enseñanza durante veinte años en Europa, ingresó a Costa Rica el 27 de noviembre de 1889, para laborar como Director del Instituto de Cartago y Profesor en el Liceo de Costa Rica. Fue un activo colaborador del Instituto Físico-Geográfico y del Museo Nacional (Céspedes Mora, 1937: 79-83; Tristán, 1966:3132; Páez, 1994:66-67; Coronado, 1997:261 y Molina Jiménez, 2005:233-234).

La sólida formación académica le permitió al Dr. Rudín ocupar una posición ventajosa frente a su par costarricense y adversar las tesis catastrofistas de Flammarion referentes a los posibles efectos del gas cianógeno de la cola del cometa Halley en la atmósfera terrestre y fueron objeto de una ardua discusión científica. Por un lado, los análisis de Flammarion fueron apoyados y difundidos por el Lic. Gutiérrez en la prensa y por otro, el Dr. Rudín publicó la obra ¿El peligro del cometa Halley? (1910) que contradice las calamidades que generaría el cometa al aproximarse a la Tierra (Molina Jiménez, 2005:234).

\section{El Lic. Pedro Nolasco Gutiérrez y las instituciones científicas de Costa Rica}

La reforma educativa promovida por la administración del Gral. Bernardo Soto, indujo a la fundación de instituciones científicas como el Museo Nacional (1887), el Observatorio Meteorológico (1887), el Instituto Meteorológico Nacional (1888) y el Instituto Físico-Geográfico Nacional (1889), asociadas con el establecimiento de entidades educativas de enseñanza secundaria como el Liceo de Costa Rica (1887) y el Colegio Superior de Señoritas (1888). L La creación del Observatorio Meteorológico en el Liceo de Costa Rica al finalizar el año 1887 fue el producto de la cristalización de un proyecto científico ideado por el Dr. Streber en 1873 y retomado por el Dr. Enrique De Mira Villavicencio una década más tarde (1883). El interés de la administración del Gral. Soto a favor de la ciencia hizo cristalizar dichos proyectos, ahora retomados por Pittier, quien contó con el soporte económico e institucional de la Secretaría de Instrucción Pública y de su ministro Lic. Mauro Fernández. El Observatorio Meteorológico fue la base del 
Instituto Meteorológico Nacional (1888), entidad surgida ante la necesidad de ampliar las investigaciones meteorológicas fuera de la ciudad capital (Díaz, 2003:64-94).

El 22 de agosto de ese mismo año, se clausura la Universidad de Santo Tomás, por parte del gobierno del Gral. Bernardo Soto Alfaro (18541931), al considerarse que el país no reunía las condiciones científicas suficientes para sostener una institución de estudios superiores. Esta medida desata una fuerte polémica al interior de la intelectualidad costarricense, como lo ejemplifica este pasaje escrito por el Lic. Félix Arcadio Montero Monge (1850-1897), último rector interino de dicha entidad y prominente líder político y gremial de la época (LG, 15-VI-1890:714):

La muerte de la Universidad es un crimen y un crimen de lesa civilización, aparte de ser un parricidio de parte del ex-Ministro Fernández, porque mató á su madre intelectual, sin cuya existencia don Mauro hubiera continuado ayudando á misa que fue su primera ocupación, según el decir de las gentes de su tiempo.

No ha sido posible localizar en las fuentes alguna manifestación sobre la posición del futuro ingeniero Gutiérrez en relación con el cierre de la Universidad de Santo Tomás, pero es factible que haya sido opuesta a dicho acto, que tuvo como principal promotor al Lic. Mauro Fernández Acuña, mentor de Pittier, para el cual una institución universitaria no tenía razón de ser en Costa Rica, como lo atestigua el siguiente pasaje y cuyo discurso contradice el apoyo gubernamental al desarrollo científico que experimentaba el país en esa época (GO, 27-VII-1888:932):

La erección de una universidad implica la creación de facultades, cuyo sistema no está limitado por un objeto, sino que tiende á la generalización de los principios y á la investigación científica de los conocimientos. Se comprende sin esfuerzo que esa tendencia exige una alta cultura intelectual, imposible de obtener en países nuevos como el nuestro, donde los individuos deben dedicarse á buscar un título de competencia, una posición más fructuosa que la que pudiera procurarles la investigación puramente científica. La escuela superior, por el contrario, quiere la utilidad inmediata y da todo lo que es útil para la vida práctica.
A pesar de los problemas institucionales, la Universidad de Santo Tomás dio invaluables aportes al plano científico, entre ellos, la apertura de cátedras de física y química, contando con la presencia de un gabinete de instrumentos científicos importado de Europa en la década de 1860 (Solano, Amador y Páez, 1990:377-378 y Páez, 1994:64).

En esa época, el Instituto Meteorológico se transformaba en el Instituto Físico-Geográfico Nacional con la incorporación temporal del Museo Nacional (1889), reestructuración que obedeció al interés estatal por renovar las representaciones cartográficas de Costa Rica y así impulsar la colonización agrícola, además apoyar sus tesis frente a los reclamos fronterizos de Nicaragua y Colombia (Díaz, 2003:94-95).

La creciente institución contó con una Sección Meteorológica, siendo su primer encargado, de 1889 a 1890, el ingeniero alemán Eduard Gugolz (m. 1904). Su sucesor fue el Ing. Pedro Reitz (1890-1894), hijo de un médico alemán, quien se esmeró porque las observaciones meteorológicas se realizaran durante las horas reglamentarias, también por el mantenimiento del equipo, la reducción y análisis de los datos recabados en otros puntos del país. Para evitar el incremento del presupuesto destinado al Instituto contratando un ayudante calculador, el botánico suizo Adolphe Tonduz (1865-1921) colaboró en la confección del registro de las observaciones nocturnas, mientras Reitz concentraba su trabajo en la reducción de las curvas proporcionadas por el barógrafo, pluviómetro y actinógrafo. Este hecho constituye una prueba del nivel de cooperación entre los miembros de la comunidad científica nacional (Conejo, 1972:581 y Solano, 1999:167).

La gestión de Reitz continuó hasta septiembre de 1894, tras su renuncia por razones de salud. Le sucede en el cargo el Ing. Agrón. Austregildo Bejarano Solano (1865-1940), profesor de la División Elemental del Liceo de Costa Rica, quien realizó estudios superiores en Glembloux (Bélgica) y traductor, junto con el profesor Manuel Antonio Quirós (1853-1929), de la obra Geometría Objetiva para uso de las Escuelas Primarias (1888) de J. M. Dalseme (Anales 1893 y 1894; Conejo, 1972:608-635; Barrantes y Ruiz, 1995:49 y Rodriguez y Ruiz, 1995:90). 
Bejarano ejerció dicho puesto hasta marzo de 1895, siendo sustituido por Pedro Nolasco Gutiérrez (Fig. 1), entonces funcionario de la Dirección General de Estadística, entidad que tuvo como director al Dr. Enrique Villavicencio (1883-1893), quien había mantenido una fuerte controversia con el Dr. Pittier por la validez de los métodos empleados por la antigua Oficina de Estadística para recoger información meteorológica (Díaz, 2003:72-73). Gutiérrez continuaría con el registro de las observaciones meteorológicas hasta el cierre temporal de la institución en 1899 (Anales, 1896; Conejo, 1972:608-635 y Molina Jiménez, 2005:247).

El informe del año económico 1897-1898, elaborado por el Lic. Pedro Nolasco Gutiérrez, comunicaba el desarrollo positivo de las labores de la Sección Meteorológica: la red pluviométrica se extendió a lo largo del Ferrocarril al Atlántico, gracias al apoyo brindado por la Costa Rica Railway Company (Río Hondo, Peralta, Siquirres y Swamp Mouth). La UFCO autorizó a sus empleados la recolección de datos en forma gratuita, producto de la misma crisis que impedía al gobierno contratar personal para dichas funciones (Conejo, 1972:639).

La crisis económica internacional (1897), causada por la sobreproducción del café brasileño en el mercado mundial (Acuña y Molina, 1991:148; Hall, 1991:42-43 y Blanco, 1997:227), tuvo sus repercusiones en los proyectos científicos nacionales: los fondos para financiar los proyectos de investigación científica del Instituto Físico-Geográfico escasearon, su presupuesto se redujo a cero pesos y el gobierno lo clausura temporalmente el 6 de enero de 1899 por "razones económicas plenamente justificadas" (República de Costa Rica, sf: XXI; Eakin, 1999:133 y Yacher, 2000:4).

Aunque la Sección Geográfica paralizó sus operaciones, la Sección Meteorológica continuó con el registro diario de las observaciones a cargo del Lic. Gutiérrez por el interés gubernamental del fomento de las actividades agrícolas (MNCR, 8553). La recuperación económica experimentada al despertar el siglo XX favorece la reapertura del Instituto Físico-Geográfico, la reorganización de sus labores y la reincorporación del Museo Nacional el 1 de febrero de 1901. El Servicio
Meteorológico continuaba funcionando con regularidad, igual que las operaciones de las veinticuatro estaciones pluviométricas, dotadas del instrumental necesario para recabar informes sobre precipitaciones y temperaturas (República de Costa Rica, sf:XXI y Eakin, 1999:134).

No obstante, por razones políticas y laborales, Pittier renuncia a la dirección del Instituto en 1904 y ocupa el cargo de director el Prof. Anastasio Alfaro González (1865-1951), entonces Secretario del Museo Nacional (Díaz, 2003:137).

En ese mismo año se suscitó una polémica entre este científico y el Lic. Gutiérrez. El primero, por su formación científica de influencia positivista rechazaba los planteamientos astrometeorológicos del segundo al atribuir la incidencia directa de los fenómenos astronómicos en los meteorológicos y geológicos (Cf. Conejo, 1972:31-33 y 36-37). Una evidencia de ello es la publicación de un artículo con ocasión de los sismos del 20 de diciembre de 1904 y el 20 de enero de 1905, ocurridos en días de luna llena, donde Pittier criticaba fuertemente las posiciones astrometeorológicas de Gutiérrez (González Víquez, 1910:105, cf. Miyamura, 1980:124):

[está] lejos de mí la idea de culpar al astro de las noches por tales calamidades! Creo que en el estado actual de nuestros conocimientos, no se puede establecer con fundamento paralelismo casual alguno entre los fenómenos seísmicos, y el estudio de las obras modernas sobre la materia me ha confirmado en esta opinión.

Cabe señalar que al inicio de su carrera en Costa Rica, Pittier sospechaba, como era usual en esa época, una relación directa existente entre los fenómenos sismológicos y los meteorológicos como lo demuestra este pasaje escrito en 1888 (Pittier, 1888:47):

Es muy notable, por ejemplo, que el promedio más elevado de temblores toca a principios de la estación lluviosa; pero no se puede olvidar tampoco el hecho de que esta época coincide con la del cambio en el régimen de los vientos. Muy bien se podría atribuir á estos últimos aquel balanceo periódico del suelo mientras la lluvia y la penetración del agua por infiltración en los focos volcánicos explicaría de otro lado los estremecimientos intermitentes de nuestros temibles vecinos. 
La continuidad de las observaciones tras la renuncia de Pittier en 1904 demuestra que el Observatorio Nacional prosiguió con sus labores habituales gracias al empeño estatal y a la comunidad científica en el sostenimiento de las investigaciones meteorológicas. El gobierno asignó una partida de 5580 colones al Instituto Físico-Geográfico y renueva el contrato con el Lic. Pedro Nolasco Gutiérrez como Auxiliar del Observatorio (Cf. Sáenz Maroto, 1970:1000 y Molina Jiménez, 2005:247).

El Lic. Gutiérrez, a pesar de las críticas vertidas por Pittier en la prensa (González Víquez, 1910:105-107 y Conejo, 1972: 278-280) prosiguió sus trabajos científicos, centrados principalmente en el cálculo de coordenadas geográficas, husos horarios, temperaturas, presión atmosférica y declinación magnética de varias localidades y puntos destacados de la geografía costarricense, ayudado por el Ing. Leonidas Carranza y algunos sacerdotes de su tiempo. Muchos cálculos y análisis tuvieron como punto de referencia los templos católicos (AMNCR, 8517:11-18).

Los cálculos y estudios determinaron en forma más precisa, la posición geográfica del observatorio por medio de observaciones de ocultaciones de estrellas y eclipses solares en 1905 y fueron adoptados por el Instituto para sus publicaciones (Anales, 1896:75c). Estos datos se consideraron oficiales y fueron confrontados al asociarlos con las coordenadas establecidas a partir de los meridianos de París, Greenwich, Nueva York y Madrid; de los Observatorios de San Fernando de Cádiz, Madrid y Tacubaya (México); del Observatorio Naval de Washington; la isla de Hierro (Canarias) y las basílicas del Santo Sepulcro (Jerusalén) y San Pedro (Roma), las catedrales de San Pablo (Londres) y de San José (Costa Rica), el Gran Hotel de Puerto Limón y la iglesia de Puntarenas (Costa Rica). Esta labor demuestra el conocimiento científico del Lic. Gutiérrez al efectuar dichos cálculos basándose en datos suministrados por la bibliografía de la época, entre ellos, la Tabla del conocimiento de los tiempos (Díaz, 2005:295).

Las observaciones solares que hizo Gutiérrez entre el 21 de junio (solsticio de verano) y el 20 de setiembre de 1905 (equinoccio de otoño), le permitieron calcular la hora para la ciudad de San
José, también elaborar informes de temperatura, presión atmosférica y declinación magnética (AMNCR, 8550). En este mismo año, el Ing. Gutiérrez estableció un sencillo sistema de información meteorológica y horaria usando luces de colores, colocadas en la azotea del Observatorio e inspirada en los sistemas de previsión meteorológica introducidos en Costa Rica para la seguridad de la navegación marítima en su ciudad natal (1879) (LR, 28-XII-1905:3 y Solano, 1999:160):

[Luces] Fijas. - Amarilla, [tiempo] dudoso; Verde, buen tiempo. Roja, tempestad. Extinción de luces roja y verde que [los fenómenos] han aparecido cinco minutos antes de la hora,

hora exacta. Azul, reservada para otras señales.

El aporte anterior, es otro ejemplo del interés de las autoridades costarricenses por transitar y adoptar medidas científicas que mitiguen en la sociedad costarricense los efectos de los fenómenos atmosféricos. Este sistema de alerta del Lic. Pedro Nolasco Gutiérrez pudo haberse inspirado en las disposiciones que el gobierno adoptaba en la década de 1870 , cuando efectuaba sus primeras observaciones meteorológicas: el señor Rafael Machado Jáuregui (1832-1906) de la Secretaría de Relaciones Exteriores emitió una correspondencia del 13 y 16 de agosto de 1879 , en el que aceptaba el sistema de alerta basado en banderas y antorchas para el aviso de la niebla y de otras emergencias relacionadas con aspectos meteorológicos o de salvamento para las embarcaciones del gobierno estadounidense. Este sistema de prevención había sido inventado por el General Albert. J. Myer, quien cumplió un papel crucial en el fomento de las relaciones científicas entre la Oficina del Tiempo de los Estados Unidos en Washington DC y el gobierno de Costa Rica (Solano, 1999:160). Con relación a este sistema de alerta, se siguió aplicando aún después de la salida del Lic. Pedro Nolasco Gutiérrez del Instituto Físico-Geográfico, sin embargo, en la prensa se expuso el malestar por este sistema que aducían no tendría ningún sentido si lo aplicaba otra persona que no fuera Gutiérrez, pues era el único que había hecho un seguimiento adecuado de la astronomía y la astrología (EI, 23-IV1910):

[...] nada hemos visto tan ridículo como lo que actualmente está pasando con las señales 
del Observatorio. Admitimos perfectamente que cuando don Pedro Nolasco intervenía en las observaciones, se aprovechara de toda su larga práctica ... pero no existiendo en ese centro científico nadie que haya dedicado su tiempo a estudios astrológicos ni astronómicos, nos parece que el mismo significado tiene para el público en general que en la torre del Observatorio aparezca una luz roja, que traduciríamos en peligro inminente, como una luz azul, que entenderíamos por tiempo bonacible [...]

La continuidad de los estudios meteorológicos se vio favorecida por la presencia de la Sociedad Nacional de Agricultura, fundada en 1903, esta asociación financió la publicación de un Boletín (1906), sucesor del extinto Boletín del Instituto Físico-Geográfico (1901-1903), que al igual que su predecesor, sus destinatarios principales fueron los grandes empresarios y propietarios agrícolas. Este documento respondía a la necesidad de este sector al mantenerlo informado sobre los avances meteorológicos, botánicos y agronómicos, para mejorar e incrementar la productividad de sus cosechas y fortalecer sus nexos como grupo social y político (Cf. BSNA, I, 1, 1906:1).

En este Boletín se publicaron las observaciones meteorológicas de San José efectuadas por el Lic. Pedro Nolasco Gutiérrez de enero a abril de 1906, asociando la sismicidad con el estado del tiempo e incluyendo las marcas extremas de humedad y actividad eléctrica atmosférica. También publicó una tabla de "líneas loxodrómicas y coordenadas de Costa Rica", con base en cálculos astronómicos en un año caracterizado por la presencia de grandes temporales que afectaron numerosos caminos, viviendas y cosechas, daños valorados en más de 150000 colones (Gutiérrez, 1906a:15-23, BSNA, 1906:47; Gutiérrez, 1906b:94 y Sáenz Maroto, 1970:1001).

No obstante, la acusiosidad y esmero en la toma de observaciones, Gutiérrez notó las limitaciones generadas por la escasez de recursos asignados a la Sección Meteorológica, afectando la realización de algunas actividades (Gutiérrez, 1906a:18). El texto que sigue pone en evidencia esta aseveración:

El estudio de la temperatura en el suelo á diversas profundidades, del ozono y de la radiación solar y terrestre, se darán en cuanto se restablezca con los instrumentos pedidos al efecto.
El 17 de noviembre de 1907, el inmigrante español Francisco Lloret Bellido (i?-1909) funda la Sociedad Geológica de Costa Rica (LPL, 283-1909:2 y Peraldo, 2003). Entre los miembros de esta sociedad aparece el nombre de nuestro biografiado Pedro Nolasco Gutiérrez. No se tienen noticias sobre los estudios que se lograron en el seno de esta sociedad, solamente las noticias que han llegado hasta nuestro tiempo respecto a la sociedad fueron dos excursiones, una al volcán Irazú cuyo objetivo posiblemente fueron las observaciones meteorológicas y otra a Talamanca y al Valle del General para estudiar la estructura geológica y las minas de carbón (Peraldo, 2002). No obstante, es posible que en la corta vida de la Sociedad, el Lic. Pedro Nolasco Gutiérrez haya participado en sus actividades.

Para 1908, con ocasión del eclipse anular de sol del 28 de junio, el Lic. Pedro Nolasco Gutiérrez realiza cálculos elementales y un diagrama para explicar el fenómeno (Fig. 2). No obstante, en Costa Rica fue visto como un eclipse parcial y se podían observar cerca del Sol los planetas visibles (Saturno, Mercurio, Venus, Marte y Júpiter) y los invisibles por telescopio (Neptuno y Urano) (Díaz, 2005:296). Amador y Solano (1991:4-5) destacan que la información publicada en torno a este eclipse excluía sugerencias en cuanto a medidas de seguridad para observarlo, al recomendarse el uso de unos "simples anteojos" porque se conocía muy poco de los efectos de los rayos ultravioleta en la vista humana.

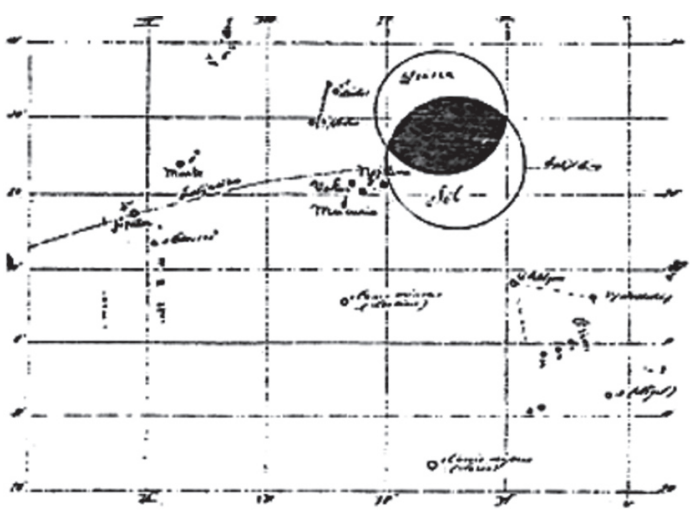

Fig. 2: Mapa astronómico del eclipse anular de sol del 28 de junio de 1908 de Pedro Nolasco (tomado de Amador y Solano,1991). La figura se localiza en el repositorio correspondiente a este artículo. 
Al finalizar la década de 1900, el Instituto Físico-Geográfico, exiguo en recursos, fue integrado por su Director Alfaro al Museo Nacional de Costa Rica (1910), debido al interés que despertaron en el país los trabajos arqueológicos, entre ellos, los del sueco Carl Hatmann (1862-1941), quien introdujo la arqueología científica en el territorio costarricense (Hartmann, 1991; Corrales, 2003:274-276 y Solórzano, 2003:256-259). En realidad, el gobierno clausuró el Instituto FísicoGeográfico y transfirió al Museo la responsabilidad de mantener el Observatorio Meteorológico y el Herbario Nacional (Eakin, 1999:135-136).

Tras el paso del cometa Halley en 1910, del que se conserva un diagrama sobre su presencia en el cielo nocturno costarricense (Fig. 3) y una vez concluida la fase sísmica que caracterizó el período, el Lic. Gutiérrez continuó sus trabajos de agrimensura que le permitieron integrarse en una efímera Comisión de Límites con Panamá organizada en ese mismo año y de la cual se retira por razones de salud (LI, 15-XI-1910:3). También en 1910, el presidente saliente Cleto González Víquez publica la obra Temblores, terremotos, inundaciones y erupciones volcánicas en Costa Rica (1608-1910), donde menciona algunos registros de sismos históricos recabados por el Lic. Gutiérrez pero sin aludir al cometa como causante del terremoto de Cartago (cf. Molina Jiménez, 2005:266).

\section{Ocaso de una turbulenta carrera científica (1911-1918)}

El Lic. Pedro Nolasco Gutiérrez renuncia a su cargo de Auxiliar del Museo Nacional y las autoridades de esta institución, encabezadas por el Prof. Alfaro convinieron en la división del Observatorio Meteorológico en dos secciones: el Servicio Meteorológico y el Sismológico, el primero encomendado al Ing. Rafael Tristán Fernández (1882-1969) y el segundo, a Pablo Biolley Constantine (m. 1919), quien estuvo al frente de la Sección Meteorológica tras la salida del Lic. Gutiérrez de la institución (Díaz, 2003:184). La renuncia, pudo ser una separación obligada, a juzgar por una nota periodística que así lo insinúa: "[...] es un delito de lesa astronomía lo que han hecho los señores de las altas esferas políticas al separarlo de su nido cuando no se sabe si no serán ya pocos los días que le restan para que siga dando sus acertados pronósticos sobre el tiempo [...]"(EI, 20-IV-1910, cf. Molina Jiménez, 2005:252-253).

El Ing. Tristán prosiguió la labor de su predecesor en la confección de registros meteorológicos para la ciudad de San José, centrados en la observación reglamentaria de la temperatura al aire libre y a la sombra, nebulosidad, humedad relativa y absoluta, presión atmosférica reducida a $0^{\circ} \mathrm{C}$, temperatura del suelo, días de lluvia, frecuencia y velocidad del viento por segundo y algunos de estos reportes mensuales fueron publicados en el Boletín de Fomento (1912) (AMNCR, 8515: 5; Tristán, 1912: 833-842 y Eakin, 1999: 135-136).

Además de continuar con la edición de almanaques (Fig. 4), el Lic. Gutiérrez publicó el texto "Resumen de la temperatura media en grados Celsius al aire libre observada en el Instituto Físico-Geográfico de San José de Costa Rica, por los Ingenieros Pedro Reitz y Pedro Gutiérrez en los años 1889 a 1897" (1912-1913), síntesis de los datos de temperatura recabados por el Observatorio Nacional en dicho período (Calvert \& Calvert, 1917:528).

Gutiérrez también publicó una de sus últimas obras, Parte de trabajos astronómicos y geodésicos hechos y recopilados por el Ingeniero topógrafo que suscribe, para el mapa y geografía de Costa Rica (1914) en los que incluye "la situación astronómica, declinación magnética, temperatura media anual, latitud, longitud y altura sobre el nivel del mar de una gran cantidad de lugares" del país y prueba una vez más la sólida preparación científica que tuvo (Dobles, 1928: 444). Esta obra fue citada dentro del compendio de obras científicas referentes a la Historia Natural de Costa Rica recopilada por Amelia (1876- $i$ ?) 


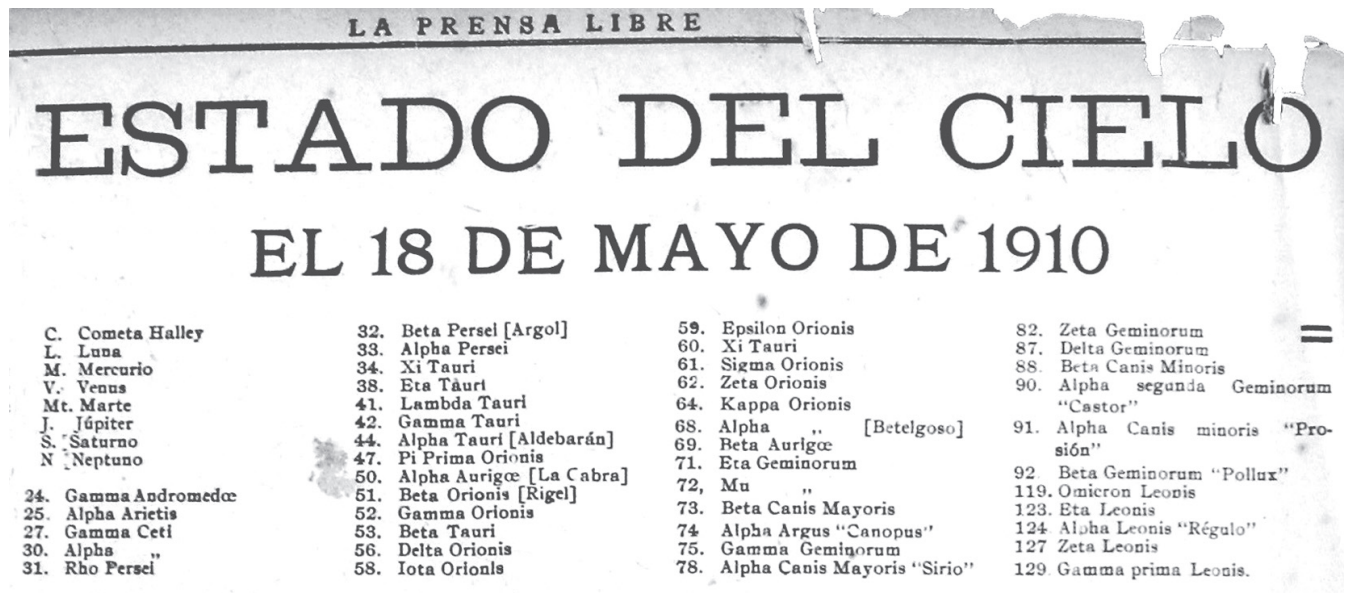

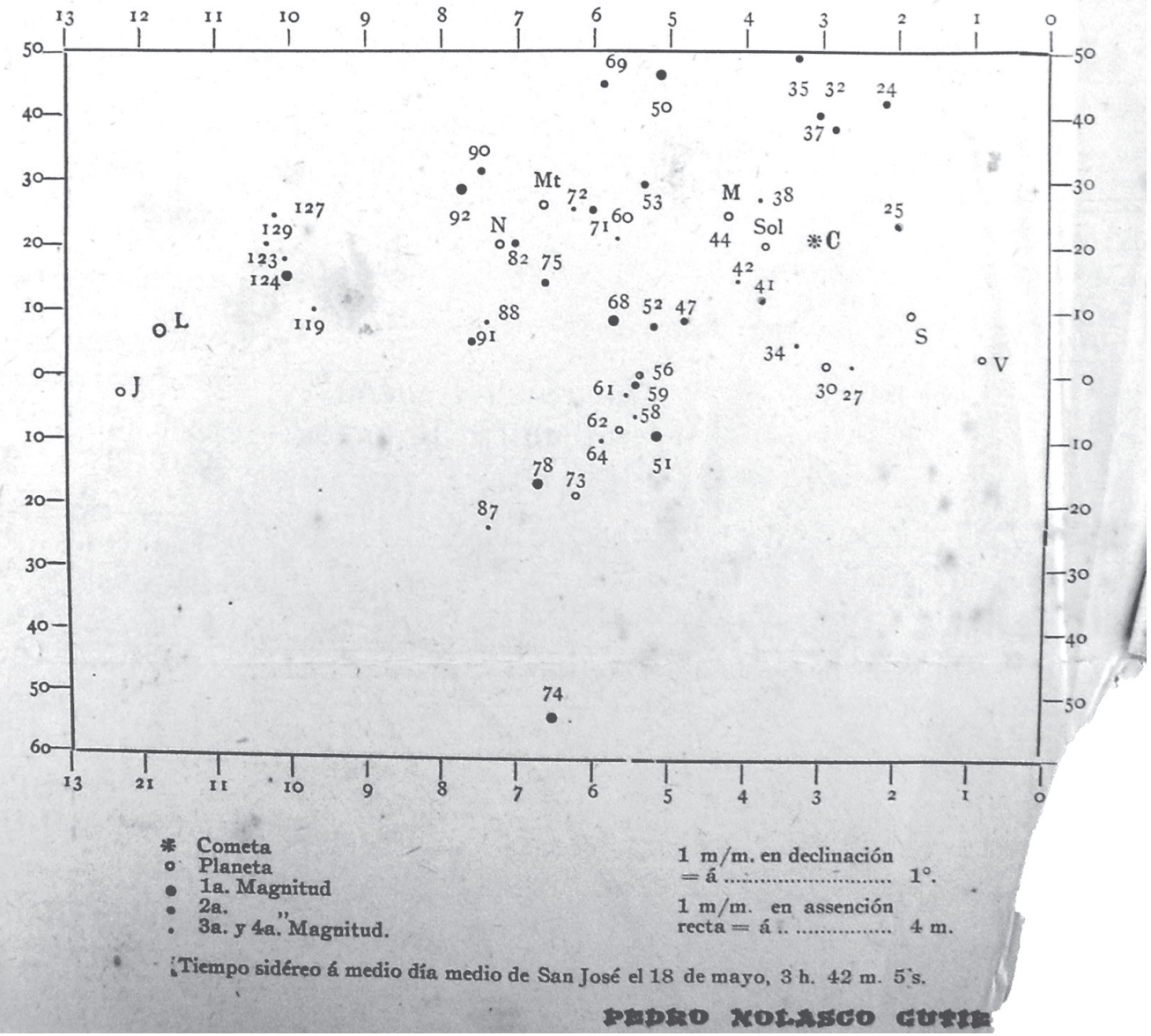

Fig. 3: Diagrama del paso del cometa Halley en 1910. Tomado del periódico La Prensa Libre del 13 de mayo de 1910, página 3. 


\section{Almanaque de abrii de 1911 por Pedro N. Gutiérrez}

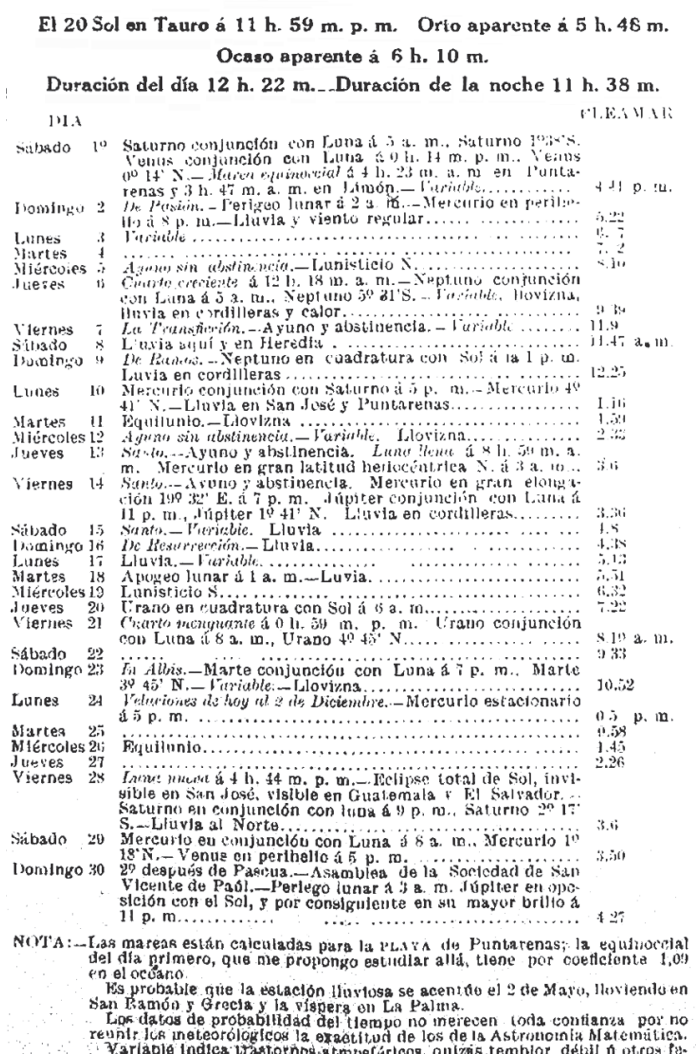

Fig. 4: Detalle del almanaque del Lic. Pedro Nolasco Gutiérrez para abril de 1911. Tomado del periódico La Información del 5 de abril de 1911, página 2 (La figura se localiza en el repositorio correspondiente a este artículo).

y Phillip Powell Calvert (1871-1961) (Calvert \& Calvert, 1917:522).

Posteriormente se dedicó a la práctica de la astronomía con el Dr. Rudín (LI, 4-II-1916:3), con quien efectuó una serie de observaciones a raíz del eclipse de Sol del 3 de febrero de 1916 que en Costa Rica fue parcial (LI, 4-II-1916:3). Atrás había quedado la rivalidad ocasionada por el avistamiento del cometa Halley y ahora, ambos intercambiaban sus opiniones acerca del fenómeno en la residencia del profesor suizo:

Pedrito acompañó al señor Rudín en toda la jornada atendiendo y explicando a los visitantes el resultado de las impresiones científicas adquiridas.
Un hecho de trascendental importancia para la historia de la meteorología costarricense fue la visita del meteorólogo y geólogo cubano, Mariano Valencia, seudónimo de Mariano Pastor Pérez, autor de numerosas publicaciones científicas en libros, periódicos y revistas cubanas, quien estuvo realizando investigaciones meteorológicas y sismológicas en Costa Rica entre noviembre de 1917 y abril de 1918, aprovechando la actividad del volcán Irazú y promocionando la idea de establecer un Instituto de Pronóstico Meteorológico para el área centroamericana que nunca se concretó por falta de interés de los gobiernos del istmo (LPL, 20-XI-1917:2). En Costa Rica, tuvo la oportunidad de tratar con intelectuales y científicos de la talla del Ing. Rafael Tristán, del Prof. Roberto Brenes Mesén (1874-1947), los escritores Carlos Gagini (1865-1925) y Modesto Martínez (1884- $i$ ?), el periodista Francisco Borges (m. 1914) y el Lic. Pedro Nolasco Gutiérrez, con quienes pudo intercambiar información científica relacionada con el comportamiento del clima y la sismología nacional (LPL, 20-XI-1917:3, 26-XI1917:3 y 11-XII-1917:3).

El diario La Información, con fecha del 18 de enero de 1918, reproduce uno de sus últimos "aciertos" aunque haya ocurrido con tan solo un día de retraso (LI, 20-I-1918:4):

El día 18 [de enero de 1918], es decir, viernes, lo marcó don Pedro "algo crítico", -según él nos informa- porque se cumplían 19 y 11 años que con la misma edad de la Luna, tembló (aproximidad de la conjunción en 1918 de la misma con Venus y muchas manchas solares que actualmente observa don Pedro.

Ayer sábado [19 de enero], a las 12 y 15 en los relojes públicos (que están con un adelanto de más de 15 minutos, tembló sintiéndose el movimiento con alguna intensidad en San Francisco de La Sabana, coincidiendo con lo marcado en su Almanaque, "variables" (quizá débiles temblores) los días 19 y 21.

Finalmente, el Lic. Pedro Nolasco Gutiérrez muere en San José a la edad de 63 años el 11 de julio de 1918. Su funeral, celebrado en la Catedral Metropolitana, fue costeado por el Estado y contó con la participación de la Facultad Técnica de la República, entidad que agrupaba 
a los ingenieros del país (LPL, 11-VII-1918:2 y Oconitrillo, 1985:162, cf. Obregón Quesada, 2005:70-72). Sus restos fueron sepultados en el Cementerio General de la capital, en una bóveda donde fue sepultada su hermana Etilma (m. 1958) (AOCGSJ, 8:307). Ella, junto con su otra hermana Micaela, solicitan en 1941 al gobierno de su pariente Lic. Rafael Ángel Calderón Guardia (1900-1970), una pensión en reconocimiento del quehacer científico efectuado por su hermano durante varias décadas por lo que se les concedió una modesta suma (CLD, 1941, II:906). Finalmente, los restos de Etilma y Pedro Nolasco Gutiérrez, fueron trasladados al osario del Cementerio General josefino, donde descansan hasta el día de hoy (Fig. 5).

\section{La sismología vista desde las hipótesis de don Pedro Nolazco Gutiérrez}

Al principio este artículo empezó narrando sobre el cometa Halley que fue para muchos, un heraldo que anunció el terremoto de Cartago de 1910. De hecho en las supersticiones y agüeros los cometas siempre han sido vistos como calamidades o anuncios de estas. En el México prehispánico, el cometa fue uno de los anuncios de la debacle del Imperio Azteca, como los refiere Fray Diego Durán (Acosta, 2001). Como lo refiere Acosta (2001) para un sismo ocurrido en México en 1567 “...habiéndose advertido varios cometas, sobrevino terremoto que arruinó varias iglesias...”. En la prensa de 1910, se comentó insistentemente sobre los malos agüeros que los cometas generaban en la sociedad testigo de su paso. La prensa exacerbó el temor popular con la publicación de notas que trataron de reafirmar el pensamiento catastrofista popular y de algunos científicos. Por ejemplo, en un reportaje periodístico de 1910, se hace alusión a la aparición del Halley en el siglo VIII cuando “....Roma en los últimos estertores de la agonía abandonaba a las hordas de los bárbaros sus más bellas y opulentas ciudades...", el mismo reportaje mencionaba que en la Edad Media reapareció juntamente cuando la peste negra asolaba Europa, y finalmente se refirió que apareció nuevamente durante la caída

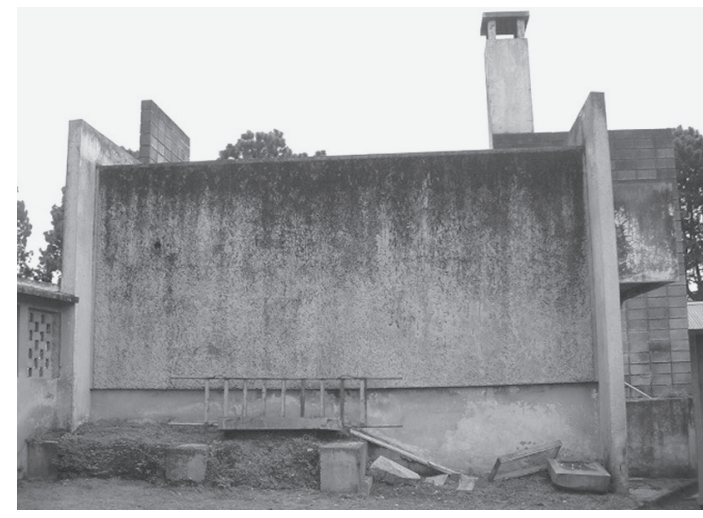

Fig. 5: Osario del Cementerio General de San José donde descansan los restos del Lic. Geom.. Pedro Nolasco Gutiérrez y su hermana Etilma. Colección particular del Lic. Ronald Díaz Bolaños

del Imperio Romano de Oriente a raíz de la toma de Constantinopla por los turcos otomanos en 1453 (EI, 28-I-1910).

En tales situaciones, cuando las personas sienten que está en juego su seguridad, tienden a consultar a las personas que elevan como mentores del evento que en ese momento está teniendo lugar. Es así que por esa época, el científico idóneo para consultarle fue sin duda don Pedro Nolasco. Este grado de popularidad del Lic. Nolasco Gutiérrez, se confirma en el siguiente extracto de una nota periodística de 1910: “[...] el frente de la morada de don Pedro es una especie de romería, pues todos se acercan á él en demanda de datos sobre los temblores, sobre la presencia del cometa en el cielo y mil detalles más con que las gentes abruman a este buen viejo, ansiosas de saber si en efecto se acerca el fin del mundo [...]" (EI, 20-IV-1910).

La fama de este científico se debe a que sin duda fue uno de los representantes más entusiastas de los estudios geofísicos de fines del siglo XIX y principios del siglo XX. En este segmento se comenta un informe que dio a conocer Gutiérrez, de un trabajo del astrónomo Guillermo Molina, defendiendo sus tesis, pero que incluye información de su autoría. El artículo en cuestión lo denominó "Terremotos y tempestades" y fue publicado en el periódico La Prensa Libre del 11 de julio de 1900. En este artículo se trata de relacionar la actividad sísmica con la meteorología y astronomía. 
Indica que mediante algunos cálculos llegó a encontrar un ciclo astronómico de 56 años, en donde el Sol, la Luna y la Tierra se encuentran casi en la misma posición y en donde el Sol exhibe las mismas manchas. Para esto se sirvió de cálculos a partir de la lunación que equivalen a dos meses sinódicos (el mes lunar sinódico es equivalente al tiempo entre una conjunción entre la Luna y el Sol, y otra, o sea cada luna nueva) usando en su cálculo 716 lunaciones y 61 revoluciones nodales. Define su ciclo como más aproximado por que en él se suceden casi los mismos eventos meteorológicos que en los otros ciclos calculados por otros científicos, aparte que reconoce, en él usó elementos que otros científicos no tenían a disposición cuando calcularon sus ciclos. Siempre en función del trabajo realizado por Guillermo Molina, refiere que su ciclo se acerca más al de 57 años calculado por Molina con relación a determinados temblores.

El elemento que incorporó en sus cálculos fue el periodo completo de las manchas solares. Indica que ellas alteran la brújula y esto lo hizo pensar que periódicamente producen corrientes eléctricas entre los volcanes que considera como grandes válvulas de seguridad, además pensaba que como está demostrado la influencia del sol y la luna en el flujo y reflujo de las mareas, entonces por que no ha de afectar a las condiciones atmosféricas.

Hasta aquí ese artículo se refiere del ciclo de 56 años calculado mediante observaciones astronómicas y resalta el hecho de que no hace una clara separación entre los eventos estrictamente atmosféricos de los geológicos, lo cual no es de extrañar por cuanto en esa época era aceptado por muchos científicos la relación directa entre la atmósfera y los eventos geológicos desencadenados por corrientes eléctricas denominadas por algunos como corrientes telúricas.

Es importante anotar que nuestros aborígenes computaban el tiempo por ciclos, tales como las culturas azteca y maya. En Nicaragua, por ejemplo los nicaraos, de fuerte influencia azteca, cada 52 años se produce una crisis cósmica e inicia el nuevo ciclo solar, pero cuando se llega a completar este ciclo, se creía que se producirían catástrofes cósmicas (Mazzacurati, 2004). Es relevante ver que estos ciclos se relacionan con ciclos solares, tal como Nolasco propone para calcular su ciclo de 56 años como anteriormente se indicó. En este sentido, tanto los aztecas como las culturas de Nicaragua encendían el fuego nuevo al inicio de cada ciclo.

Si don Pedro Nolasco tenía conocimiento de la cosmogonía de los aborígenes americanos no lo sabemos, pero es realmente interesante la semejanza de la duración de los ciclos de los aborígenes y el calculado por Nolasco.

Gutiérrez proporciona algunos ejemplos para apoyar su tesis. Refiere que el sismo del 21 de junio de 1900, terremoto de Nicoya, tiene relación con los fenómenos de 1844 , y con los de 1862 y 1881, pues todos estos temblores, según sus cálculos tuvieron lugar como 4 días después del apogeo lunar (punto en que la luna se encuentra más alejada de la Tierra) lo cual es extraño porque se consideraría más bien que entre más cercana esté la luna aumenta su fuerza gravitacional sobre nuestro planeta.

Otro ejemplo es la coincidencia en cuanto que el día 19 de junio de 1900 coincidió con el equilunio y el 30 de junio de 1888 coincidió con dos eventos astronómicos importantes: el apogeo y el equilunio. En ese día ocurrieron grandes tempestades climáticas. Además recuerda que en 1888 un informe de un científico que seguía esa misma línea de investigación refirió que entre el 19 al 23 de diciembre de 1888 era un periodo peligroso por temblores, recordemos que el 30 de diciembre de 1888 ocurrió el terremoto de Fraijanes. Sin embargo, aun cuando considera que 1888 como 1900 comparten semejanzas astronómicas, no se puede adelantar ese tipo de conclusiones para 1900 porque a nivel de sismos se debe considerar un ciclo más perfecto. Con esto está indicando que la predicción de sismos obedece a parámetros más complejos que los requeridos para la predicción de otros eventos naturales, tales como los climáticos. De hecho, en diciembre de 1900 no ocurrió ningún temblor de importancia.

Los calendarios que confeccionara el Lic. Pedro Nolasco Gutiérrez, posiblemente fueron elaborados en función de estas investigaciones sobre los eventos astronómicos, pues en varias ocasiones indicó días peligrosos, que posiblemente por sus cálculos cumplían con el ciclo que 
estableció y con semejanzas en los eventos astronómicos para años con fuerte actividad símica o volcánica. En este sentido el calendario de 1912 hace énfasis en los días 18 a 24 de febrero, siendo así que el día 21 de febrero de ese año ocurrió un terremoto destructivo en Tres Ríos (EN, 22II-1912) y cuando ocurrió el terremoto del 13 de abril de 1910 en su almanaque había indicado el día 12 como "sospechoso" (EN, 14-IV-1910). Esto se confirma con un reportaje de un diario costarricense al que se le denominó "el brujo".

\section{Otros aspectos de interés relacionados a la figura del Lic. Pedro Nolasco Gutiérrez}

Desde la palestra popular, es muy interesante analizar la época de 1910, pues se amalgamó un periodo de alta sismicidad en plena propaganda electoral, que crearon una atmósfera política cargada, matizada por el paso de un cometa que llenaba de horror al pueblo y, en esta simbiosis uno de los elementos que la amalgamaron fue, sin duda, la figura del Lic. Pedro Nolasco Gutiérrez y sus predicciones que como se ha visto, revistieron una gran popularidad. Aunque el Lic. Pedro Nolasco Gutiérrez pudo participar en política dos décadas atrás, no obstante, su carácter introvertido nunca lo introdujo de manera fuerte en las arenas de la política de 1910, más si su popularidad y su ciencia dieron origen a diversos comentarios periodísticos sobre la campaña política de ese año que, en ciertos momentos, estuvo sumamente caldeada. Se reprodujo en este apartado una poesía satírica hacia los republicanos y parte de un irónico diálogo contra el Partido Civilista del Lic. Rafael Iglesias Castro (1861-1924). En la siguiente poesía, se conjuga el paso del cometa, la toma de poder el 8 de mayo de 1910 y la derrota del dictador liberal José Santos Zelaya (18531919) en Nicaragua (EI, 9-IV-1910)

\section{¡Al cometa;}

La cosa será después del 8 de mayo.

\section{Se susurra tenazmente en esta bendita tierra que se hacen preparativos con premura y exigencia}

\author{
para el segundo congreso, \\ que es la segunda asamblea \\ que se celebrará en este año \\ La gente politiquera \\ del bando republicano, \\ bando de gente resuelta \\ para atrapar del gobierno \\ las tan deseadas riendas. \\ Pero también hay personas- \\ el sabio Nolasco entre ellas,- \\ que dicen en sus adentros: \\ Hum! La cosa está muy seria; \\ ¡otra convención en marzo! \\ Infunde mucha sospecha, \\ pues nosotros no sabemos \\ si se los lleva el "cometa". \\ Pasó la lucha política, \\ ya se vio de que manera: \\ Peleándose los partidos \\ las elecciones primeras \\ y saliendo los azules \\ triunfantes en la pelea \\ con la ayuda de don Cleto \\ $y$ de la vecina tierra; \\ pero ya no nos importa \\ que fuera o no fuera cierta \\ la especie que se corrió \\ en forma de una sospecha, \\ de que los del bando azul \\ jurarán con plata ajena, \\ porque hasta el mismo Zelaya \\ se lo ha llevado el "cometa"
}

No queremos retraer la popularidad que Nolasco gozó en ese periodo de nuestra historia, pues sería como eliminar una gran parte de la esencia que este científico generó en la sociedad de principios del siglo XX con cuya omisión este ensayo biográfico estaría incompleto. En la anterior poesía se juega con las creencias de la época con relación a los males que traería el cometa Halley para la ciudadanía costarricense, pero también se hace una sátira hacia el partido Fernandista, como se le decía en la prensa, cuyo líder era el Lic. Máximo Fernández Alvarado (1858-1933). En dicha sátira se involucra al Lic. Pedro Nolasco Gutiérrez como figura pública y con relación a la ciencia que profesó. En otra nota periodística, redactada en forma de dialogo 
satírico hacia los partidarios civilistas, se dice que el origen de los temblores fue "[...] una máquina que tenía don Rafael Iglesias Castro, que desde el Molino la ponía a funcionar y entonces la tierra temblaba [...]" Al término del dialogo el uno de los personajes, dice: "[...] Y entonces ¿cómo don Pedro Nolasco anticipó el temblor del 13?”. La respuesta fue que "[...] don Pedro era civilistón y debe estar de acuerdo con don Rafael [...]"(EI, 24-IV-1910). A tal punto se popularizaron las predicciones del Lic. Pedro Nolasco Gutiérrez que en la noticia de marras, se comenta que: "[...] $Y$ no es eso lo peor, sino que dicen que cuando esté don Ricardo [Jiménez Oreamuno, candidato por el Partido Republicano y ganador en esas elecciones] en el poder vendrá un terremoto que hará brincar al presidente electo desde la silla que ya calentó primero don Cleto [González Víquez, presidente saliente] [...]"(EI, 24-IV-1910).

Todas las figuras públicas, sean estas políticas o científicas, son susceptibles de ser tomados para hacer los bromas y sátiras políticas del momento. Con esta muestra de una mezcla entre lo sísmico, lo político y las predicciones del Lic. Pedro Nolasco Gutiérrez se demuestra que la dinámica social siempre mezcla lo formal con lo informal para mover al pensamiento popular.

\section{CONCLUSIONES}

Al analizar detenidamente la vida y aportes del Lic. Geóm. Pedro Nolasco Gutiérrez a partir de las fuentes documentales investigadas, es factible identificar su papel dentro de los procesos de institucionalización de la actividad científica en Costa Rica. Ciertamente, aunque no tuvo una formación científica universitaria, a diferencia de otros contemporáneos suyos como Pittier, Rudín o Biolley, sus conocimientos autodidácticos le hicieron posible su ascenso social al interior de la comunidad científica, gracias al conocimiento que tenía para investigar, registrar y analizar los fenómenos meteorológicos, geológicos y astronómicos. Esta condición lo hizo idóneo para trabajar en el Instituto Físico-Geográfico, la principal institución científica con que contó el país al finalizar el siglo XIX.

En su evolución profesional es palpable la influencia ejercida por el Dr. Bertoglio y el astrónomo Guillermo Molina, que alcanzaron gran renombre en el país por sus trabajos, el primero como profesor en el Instituto Nacional y en la Universidad de Santo Tomás y el segundo por sus publicaciones relacionadas con la aritmética y la astronomía. Cabe señalar, que debido a la influencia de Molina, su labor científica se vio orientada por la astrometeorología, en una época donde era usual atribuir una relación directa entre fenómenos de diversa naturaleza, en este caso, los astronómicos y los geológicos. La utilización de métodos astrológicos a la predicción de los eventos naturales no acarreaba la misma censura si se aplicaban para limitar el libre albedrío de los humanos, por lo que se consideraba posible estudiar a través de esos métodos la relación entre los fenómenos astronómicos y los geofísicos. Incluso científicos con una formación más académica que la de Gutiérrez, entre ellos Pittier, asociaba la actividad sísmica con el comportamiento meteorológico.

Sin embargo, la invención de nuevos métodos de predicción meteorológica que prescindían de las observaciones astronómicas empiezan a desarrollarse en el siglo XIX y se perfeccionan en la primera mitad del siglo XX, particularmente con la irrupción de las revolucionarias teorías desarrolladas por el meteorólogo noruego Vilhelm Bjerknes (1862-1951) y la Escuela de Bergen que transformarían la explicación de los fenómenos meteorológicos, por lo que la astrometeorología quedaría relegada al plano de las pseudociencias. La negativa de Pittier para llevar a cabo métodos de predicción más modernos en Costa Rica, favoreció la persistencia de las predicciones astrometeorológicas durante las primeras décadas del siglo XX.

El análisis de las polémicas establecidas entre Gutiérrez, Pittier y Rudín, revelan la diversidad de pensamientos presentes en la comunidad científica costarricense de finales del siglo XIX e inicios del XX. Las fuentes evidencian la discusión de ideas científicas que van desde la 
persistencia de enfoques clásicos como la astrometeorología hasta el positivismo que rechazaba de antemano la relación entre fenómenos geofísicos y astronómicos por no tener pruebas directas de tales vínculos. Tanto Gutiérrez como Pittier y Rudín difundían los resultados de sus trabajos en publicaciones como los Anales del Instituto Físico-Geográfico o en el Boletín de Fomento, los que se intercambiaban con revistas de sociedades científicas del extranjero. Incluso, publicaban trabajos en la prensa o realizaron observaciones en conjunto cuyos resultados estaban disponibles al público que acudía a presenciar fenómenos como eclipses.

Esta apertura al público favoreció la difusión de conceptos científicos entre los asistentes y entre los lectores del almanaque editado anualmente, que incluía información relacionada con eventos astronómicos, con el cambio en las estaciones y pronósticos meteorológicos de largo plazo, además de información de carácter cotidiano como las celebraciones del santoral católico. La venia eclesiástica sin duda favoreció aún más su difusión en una sociedad cuyas clases populares miraban con desconfianza las políticas civilizatorias del Estado liberal y de la intelectualidad radical del momento.

El mismo Pittier, en calidad de Director del Instituto Físico-Geográfico reconoció el trabajo científico de Gutiérrez y le encomendó la jefatura de la Sección Meteorológica en el último lustro del siglo XIX. Desde su posición, el licenciado geómetra registró la actividad sísmica y fenómenos astronómicos destacados, entre ellos, la caída de aerolitos.

Posteriormente, se desempeña como auxiliar del Observatorio en la primera década del siglo $\mathrm{XX}$, por lo que aprovecha su nuevo empleo para realizar observaciones meteorológicas, sismológicas y astronómicas en la capital. Su puesto le permitió intercambiar información y debatir ideas con los científicos Pittier y Rudín, que contaban con una formación científica más sólida y un mayor apoyo del gobierno para el ejercicio de sus labores científicas.
Por todo ello, este trabajo es un aporte para resaltar la labor de una figura que el devenir histórico ha mantenido oculta por su firme creencia en disciplinas y en enfoques teórico-metodológico que tendían a ser desplazados por la ciencia positivista de la época. Cabe ahondar más otros aspectos aún no investigados del Lic. Gutiérrez, entre ellos su posible vínculo con instituciones y sociedades científicas extranjeras y sus contactos científicos fuera del país.

\section{FUENTES PRIMARIAS}

Archivo de la Oficina del Cementerio General de San José (AOCGSJ)

Tomo 8, folio 307 (1918-1958).

Archivo del Museo Nacional de Costa Rica (AMNCR)

Inventario General de Bienes (IGB). Exp. 7961 (1888), 7999 (s.f.), 8515 (1911), 8517 (1890-1913), 8543 (1892-1898), 8550 (1905) у 8552 (1877-1878).

Archivo Histórico Arquidiocesano Mons. Bernardo Augusto Thiel Hoffmann (AHAMBATH)

Sección Audiovisual. Serie Microfilmes. Rollo T-001 (Bautizos Puntarenas. Libro 2. Folio 26. No. 40, 1855).

Sección Gobierno Eclesiástico (SGE). Serie Visitas Pastorales (SVP). Libro 5 (1899-1910).

Archivo Nacional de Costa Rica (ANCR)

Colección Particular José Fidel Tristán Fernández. Exp. 145.13 (1916).

Fondo Judicial. Serie San José Alcaldía Tercera. Exp. 4278 (1891). 
Colección de Leyes, Decretos, Acuerdos y Resoluciones de la República de Costa Rica (CLD)

Año de 1941. Segundo Semestre. Edición oficial. San José, Costa Rica. Imprenta Nacional

\section{Periódicos}

El Mentor Costarricense (EMC)

17 de agosto de 1844:224.

19 de Julio de 1845:372.

Gaceta Oficial (GO)

12 de agosto de 1885:673.

27 de julio de 1888:932.

15 de junio de 1890:714.

La Información (LI)

15 de noviembre de 1910:3.

5 de abril de 1911:2.

2 de febrero de 1916:5.

4 de febrero de 1916:3.

27 de abril de 1916:3.

La Prensa Libre (LPL)

10 de octubre de 1889:2.

30 de agosto de 1890:2.

9 de mayo de 1910:3.

13 de mayo de 1910:3.

20 de noviembre de 1917:2-3.

26 de noviembre de 1917:3.

11 de diciembre de 1917:3.

11 de julio de 1918:2.

La República (LR)

28 de diciembre de 1905:3.

La Unión Católica

14 de diciembre de 1890:3.

18 de diciembre de 1890:2-3.

22 de octubre de 1892:333-335.

3 de noviembre de 1892:347.
5 de febrero de 1893:2.

13 de mayo de 1893:581.

18 de noviembre de 1893:850.

17 de febrero de 1897:142.

El Independiente

8 de abril de 1910

9 de abril de 1910

19 de abril de 1910

20 de abril de 1910

22 de abril de 1910

23 de abril de 1910

\section{Revistas}

Anales del Instituto Físico-Geográfico Nacional. 1893-1894 y 1896.

Boletín de la Sociedad Nacional de Agricultura. 1906.

\section{REFERENCIAS}

ACUÑA ORTEGA, V. H. \& MOLINA JIMÉNEZ, I., 1991: Historia económica y social de Costa Rica (1750-1950).- 214 págs. Porvenir, San José.

AZUELA, L. F., 1996: Tres sociedades científicas en el Porfiriato.- 203 págs. UNAM, México.

AZUELA, L. F. \& Talancon, J.L., 1999: Contracorriente. La historia de la nucleoelectricidad en México (1945-1995). México. Plaza y Valdés - UNAM. 472 p.

BLANCO, A., 1997: Los médicos en Costa Rica y su influencia en el desarrollo social y económico.- 540 págs. Imprenta y Litografía Mundo Gráfico, San José.

CALVERT, A. S. \& CALVERT, P.P., 1917: A Year of Costa Rican Natural History.577 págs. The MacMillan Company, New York. 
CÉSPEDES MORA, R., 1937: Cosas que no se olvidan.- 88 págs. Imprenta Juan Arias, San José.

CONEJO, A., 1972: Materiales para una biobibliografía costarricense del Dr. Henri Pittier Dormond.- 657 págs. Universidad de Costa Rica [Tesis Lic.].

CORRALES, F., 2003: La delgada línea entre la arqueología y el coleccionismo: el interés por el pasado precolombino en el siglo XIX.- En: PERALDO, G. (comp.), 2003: Ciencia y Técnica en la Costa Rica del siglo XIX.- Ed. Tecnológica de Costa Rica, Cartago: 265-267.

DE LA CRUZ, V., 1984: Las luchas sociales en Costa Rica. 1870-1930 [4 $4^{\mathrm{a}}$ reimpr.].- 304 págs. ECR, San José.

DÍAZ, R.E., 2003: El proceso de institucionalización de la meteorología en Costa Rica (1887-1949).- 345 págs. Universidad de Costa Rica [Tesis Lic.].

DOBLES, L., 1928: Índice bibliográfico de Costa Rica. II.- 608 págs. Imprenta Lehmann, San José.

ESPASA-CALPE [s.f.]: Enciclopedia Universal Ilustrada Europeo-Americana. EspasaCalpe, Madrid. XIII:135.

FERNÁNDEZ, C., 1953: Anecdotario nacional.897 págs. Imprenta Nacional, San José.

FLAMMARION, C., 1883: La atmósfera. Descripción de los grandes fenómenos de la Naturaleza. Tomo I. Tr. por Barinaga y Corradi, L.- 467 págs. Imprenta y Librería de J. Gaspar, Madrid.

GOEBEL, A., 2006: El Ing. Manuel Víctor Dengo B. y el desarrollo tecnocientífico y empresarial en Costa Rica. Una biografía contextualizada (1840-1925).- 72 págs. Museo Histórico y Tecnológico del Grupo ICE, San José.
GONZÁLEZ, P., 1972: La Universidad de Santo Tomás: un estudio introductorio.- 181 págs. Universidad de Costa Rica [Tesis Lic.].

GONZÁLEZ, C., 1910: Temblores, terremotos, inundaciones y erupciones volcánicas en Costa Rica 1608-1910.- 200 págs. Tipografía de Avelino Alsina, San José.

HALL, C., 1991: El café y el desarrollo histórico-geográfico de Costa Rica [2 ${ }^{\text {da }}$.reimpr.].210 págs. ECR, San José.

HARDY, R., WRIGHT, P., GRIBBIN, J. \& KINGTON, J., 1983: El libro del clima. Rubio, A. M. (Tr.).- 224 págs. Hermann Blume Ediciones, Madrid.

HARTMAN, C., 1991: Arqueología costarricense (textos publicados y diarios inéditos). Ohlsson de Formoso, A. (Tr.).- 136 págs. EUCR, San José.

HERRERA, E., 1988: Los alemanes y el Estado cafetalero.- 215 págs. EUNED, San José.

HOFFMANN, C., 1976: Viajes por Costa Rica.- 217 págs. MCJD, Departamento de Publicaciones, San José.

INSTITUTO GEOGRÁFICO NACIONAL; 1989: Comisión Organizadora del Centenario. Edición conmemorativa. Cien años. Instituto Geográfico Nacional.- 198 págs. IGN, San José.

MATA, L., 1992: El cólera: historia, prevención y control.- 368 págs. EUCR, San José

MIYAMURA, S., 1980: Conocimiento sobre la sismicidad en Costa Rica.- 190 págs. EUCR, San José.

MURILLO, C., 1995: Identidades de hierro y humo. La construcción del Ferrocarril al Atlántico 1870-1890.- 158 págs. Porvenir, San José.

NÚÑEZ, F.M., 1953: Anecdotario costarricense.114 págs. Editorial Aurora Social, San José. 
OBREGÓN, R., 1955: Los Rectores de la Universidad de Santo Tomás de Costa Rica.- 184 págs. Editorial Universitaria, San José.

OBREGÓN, R., 1991: Costa Rica y la guerra contra los filibusteros.- 407 págs. Museo Histórico Cultural Juan Santamaría, Alajuela.

OBREGÓN, C., 2005: Historia de la ingeniería en Costa Rica. San José, Costa Rica.- 555 págs. Colegio Federado de Ingenieros y Arquitectos.

OCAMPO, J., 1989: Supersticiones y agüeros colombianos.- 400 págs. Editorial Nomos, Colombia.

OCONITRILLO, E., 1985: Memorias de un telegrafista... ipero de la Casa Presidencial!.217 págs. ECR, San José.

PALMER, S., 2003: From Popular Medicine to Medical Populism. Doctors, Healers, and Public Power in Costa Rica, 1800-1940.329 págs. Duke University Press, Durham.

PALUZÍE, A., 1984: Astronomía. Explorando el universo.- 536 págs. Editorial Ramón Sopena, Barcelona.

PERALDO, G., 2003: El pensamiento científico del siglo XIX y la evolución de la geología en Costa Rica y su enseñanza. En: PERALDO, G. (comp.) (2002).- Ciencia y técnica en la Costa Rica del siglo XIX.Editorial Tecnológica de Costa Rica, Cartago: 37-38.
PÉREZ, H., 1997: Breve historia contemporánea de Costa Rica.- 240 págs. Fondo de Cultura Económica, México.

REPÚBLICA DE COSTA RICA [s.f.]: Memoria de Fomento presentada al Congreso Constitucional de 1901.- 90 págs. Tipografía Nacional, San José.

RODRÍGUEZ-SALA, M.L., 2002: Exploraciones en Baja y Alta California, Escenarios y personajes, 1769-1775.- 318 págs. México. UNAM-AMATEditorial.

RODRÍGUEZ-SALA，M. L., 2002: Letrados y técnicos de los siglos XVI y XVII. Escenarios y personajes en la construcción de la actividad científica y técnica novohispana.- 336 págs. México. UNAM-IIS.

RODRÍGUEZ,E., 2005: Catástrofes y mentalidades colectivas. Las creencias religiosas ante las catátrofes en el Occidente del Valle Central (1799-1853).-210 págs. Tesis de Licenciatura en Historia. Universidad de Costa Rica.

RODRÍGUEZ-SALA, M. L. NERIA K, RAMÍREZ, V. \& TOLENTINO, A., 2004: Los cirujanos del mar en la Nueva España (1572-1820) ¿Miembros de un estamento profesional o una comunidad científica?.- 200 págs. México. UNAM. IIS. Universidad Autónoma de Nayarit. Instituto Veracruzano de la Cultura. Academia Mexicana de Cirugía.

RODRÍGUEZ-SALA, M. L., RAMÍREZ, V., TOLENTINO, A., PÉREZ, A. ., 2005: El Hospital Real de los Naturales, sus admi- 
nistradores y sus cirujanos (1531-1764) ¿Miembros de un estamento profesional o una comunidad científica?.- 198 págs. UNAM. IIS. México.

RODRÍGUEZ-SALA, M. L., RAMÍREZ, V., TOLENTINO, A., RIVERA, C., PÉREZ, A., MIRELES, A., 2005: Los cirujanos de hospitales de la Nueva España (siglos XVI y XVII) ¿Miembros de un estamento profesional o una comunidad científica?.- 460 págs. UNAM. IIS. Academia Mexicana de Cirugía. Secretaría de Salud. México.

SÁENZ, A., 1970: Historia agrícola de Costa Rica.- 964 págs. Departamento de Publicaciones UCR. San José.

SALAZAR, O., 1993: El apogeo de la república liberal en Costa Rica. 1870-1914. ( $1^{\text {a }}$ reimpr.).- 308 págs. San José Ed. UCR. San José.

SALDAÑA, J. J., 1989: Introducción a la teoría de la historia de las ciencias (2 ed.).-390 págs. UNAM. México.

SALDAÑA, J. J., 1996: (coord.) La historia social de las ciencias en América Latina.299 págs. Editorial Miguel Ángel Porrúa. México.

SCHERZER, K. VON \& WAGNER, M., 1944: La República de Costa Rica en Centro-América. Lines, J. A., Wender, E. J. y Dávila, J. (Trs.).354 págs. Imp. Lehmann. San josé.

SEGARRA, J. \& JULIÁ, J., 1907: Excursión por América. Costa Rica.- 657 págs. Imprenta de Avelino Alsina. San José.
SOLANO, F. J., 1999: El proceso de institucionalización de la meteorología en Costa Rica en el siglo XIX.- 211 págs. Universidad de Costa Rica [Tesis Lic.].

SOLANO, F. J. \& DÍAZ, R., 2005: La ciencia en Costa Rica: (1814-1914). Una mirada desde la óptica universal, latinoamericana y costarricense.70 págs. Universidad de Costa Rica [Tesis Lic.].

SOLÓRZANO, J. C., 2003: Reflexiones en torno a la historiografía y la arqueología en Costa Rica durante el siglo XIX.- En: PERALDO, G. (comp.), 2003: Ciencia y Técnica en la Costa Rica del siglo XIX.Ed. Tecnológica de Costa Rica, Cartago: 239-264.

TRISTÁN, J. F., 1966: Baratijas de antaño.- 192 págs. Ed. Costa Rica. San José.

VALVERDE, A., 1997: La ciudad de Puntarenas: Una aproximación a su historia económica y social. 1858-1930.- 198 págs. Universidad de Costa Rica [Tesis Lic.].

VIALES, R., 2000: Los liberales y la colonización de las áreas de frontera no cafetaleras: El caso de la Región Atlántica (Caribe) costarricense entre 1870 y 1930.- 431 págs. Universitat Autònoma de Barcelona [Tesis PhD.].

VIALES, R., 2003: El Colegio de Farmacéuticos y la institucionalización de la Farmacia en Costa Rica: 1902-2002.- 247 págs. Colegio de Farmacéuticos de Costa Rica. San José. 